\title{
Compensatory Relearning Following Stroke: Cellular and Plasticity Mechanisms in Rodents
}

\author{
Gustavo Balbinot ${ }^{1 *}$ and Clarissa Pedrini Schuch ${ }^{2}$ \\ ${ }^{1}$ Brain Institute, Universidade Federal do Rio Grande do Norte, Natal, Brazil, ${ }^{2}$ Graduate Program in Rehabilitation Sciences, \\ Universidade Federal de Ciências da Saúde de Porto Alegre (UFCSPA), Porto Alegre, Brazil
}

\section{OPEN ACCESS}

Edited by:

Salvatore Salomone,

Università degli Studi di Catania, Italy

Reviewed by:

Andreas R. Luft,

University of Zürich, Switzerland

Basabdatta Sen Bhattacharya,

Birla Institute of Technology and Science, Pilani - Goa Campus,

India

*Correspondence:

Gustavo Balbinot

gustavo.balbinot@hotmail.com

Specialty section:

This article was submitted to

Neuropharmacology,

a section of the journal

Frontiers in Neuroscience

Received: 29 October 2018

Accepted: 18 December 2018

Published: 31 January 2019

Citation:

Balbinot $G$ and Schuch CP (2019) Compensatory Relearning Following

Stroke: Cellular and Plasticity

Mechanisms in Rodents.

Front. Neurosci. 12:1023.

doi: 10.3389/fnins.2018.01023 von Monakow's theory of diaschisis states the functional 'standstill' of intact brain regions that are remote from a damaged area, often implied in recovery of function. Accordingly, neural plasticity and activity patterns related to recovery are also occurring at the same regions. Recovery relies on plasticity in the periinfarct and homotopic contralesional regions and involves relearning to perform movements. Seeking evidence for a relearning mechanism following stroke, we found that rodents display many features that resemble classical learning and memory mechanisms. Compensatory relearning is likely to be accompanied by gradual shaping of these regions and pathways, with participating neurons progressively adapting cortico-striato-thalamic activity and synaptic strengths at different cortico-thalamic loops - adapting function relayed by the striatum. Motor cortex functional maps are progressively reinforced and shaped by these loops as the striatum searches for different functional actions. Several cortical and striatal cellular mechanisms that influence motor learning may also influence post-stroke compensatory relearning. Future research should focus on how different neuromodulatory systems could act before, during or after rehabilitation to improve stroke recovery.

Keywords: stroke, rehabilitation, motor learning, pharmacotherapy, plasticity

\section{INTRODUCTION}

Recovery following stroke requires locating reorganization processes in the brain where the necessary motor and sensory signals converge. Once located, descriptions of mechanisms for optimization can provide neural substrates for recovery. In the cortex and striatum, waves of growth inhibiting and promoting factors related to cellular and plastic changes are triggered by the lesion. Cellular death leads to homeostatic destabilization and to a subsequent process of repair leading to partial recovery of cellular function (Carmichael, 2003). Cellular reorganization processes take place in brain regions adjacent or previously connected to the affected cells, such as: periinfarct tissue, cortico-cortical pathways, cortico-striatal pathways and cortico-thalamic pathways. Rehabilitation and pharmacological therapies are used to optimize and guide these cellular and plasticity changes. This complex recovery process following stroke involves several factors, here we suggest that cellular and plasticity mechanisms related to motor learning are likely active.

Stroke induces a permissive environment for axonal sprouting through growth-promoting proteins in the boundary zone to the ischemic core (Li et al., 1998; Carmichael et al., 2005). The permissive environment after stroke leads to cortical and corticospinal tract rewiring (Winship and Murphy, 2008; Wahl and Schwab, 2014) and other forms of long-term plasticity associated with 
learning (Hess and Donoghue, 1994; Hess et al., 1996). These changes associated with compensatory relearning are expected to produce both increases and decreases in synaptic strength distributed throughout the complex neural networks (bidirectional changes; Cohen and Castro-Alamancos, 2005). The precise homeostatic changes in order to refine synaptic connectivity and to adjust synaptic strengths to promote the stability needed for motor recovery following stroke are still poorly understood (Turrigiano and Nelson, 2004; Murphy and Corbett, 2009).

To enhance stroke recovery, the interaction of fundamental interconnected areas of research - such as motor learning and endogenous plasticity mechanisms, urgently requires new and innovative approaches (Krakauer, 2006; Krakauer et al., 2012). It has been 12 years since Krakauer suggested the relevance of motor learning for stroke recovery and rehabilitation (Krakauer, 2006). A brief review of recent clinical studies on stroke recovery highlights the positive effects of virtual reality for motor learning retention (Carregosa et al., 2018) and also in combination with transcranial stimulation (Fuentes et al., 2018) or exoskeletons (Grimm et al., 2016); and the prominent effects of constraintinduced movement therapy (CIMT) (reviewed elsewhere; Hatem et al., 2016). Motor skill relearning using CIMT is considered a promising and efficient method to improve clinical prognosis in stroke motor rehabilitation. Nevertheless, the authors highlight the need of more information about the integration of other motor skill learning techniques other than CIMT (Hatem et al., 2016). We suggest that using a reverse translation approach, preclinical stroke research may unveil the mechanisms involved in compensatory relearning to gauge the dose and timing of rehabilitation, drug therapy or the combination of both. For example, the use of pharmacotherapy in combination with physical rehabilitation before, during or after the rehabilitation section to maximize relearning effects. In this review, we merge principles and mechanisms of motor learning and stroke recovery and present a new perspective based on where and how compensatory relearning occurs.

New treatments for post-stroke impairments may depend on a better understanding of the neural mechanisms and influences of compensatory behavior (Jones, 2017). One of the challenges of understanding how compensatory relearning occurs is the fluid nature of memories, with participating brain regions dynamically shifting over time (Makino et al., 2016). To test if stroke recovery is mediated by relearning mechanisms, more studies with high temporal and spatial precision are needed (Makino et al., 2016). Recent findings suggest that the 'stroke recovery circuit' may parallel memory formation during learning tasks (Caracciolo et al., 2018); and that thalamo-cortical plasticity promotes stroke recovery (Tennant et al., 2017). These two examples highlight how temporal and spatial information needs to be integrated to unveil the mechanisms of compensatory relearning. The purpose of this review is to condense experimental findings of the large literature on motor skill learning and post-stroke recovery. We refer the reader to other recently published reviews for additional perspectives of cellular and plastic mechanisms of motor skill learning and stroke recovery. We also offer our perspectives on how to improve stroke recovery focused on compensatory relearning.

\section{THE CORTICAL CIRCUIT}

The cellular and synaptic organization of the somatosensory cortex supports the primary motor neurons and the storage capability needed to encode movements (Penfield and Rasmussen, 1950; Jankowska et al., 1975; Nudo et al., 1996a; Hosp and Luft, 2011). Movements are represented in the motor cortex in regions related to forelimb or hindlimb responses (rostral forelimb area and caudal forelimb area; Neafsey and Sievert, 1982). At each region distinct cortical layers function to receive, integrate and transmit the motor output. The cortical circuit is shaped by redundancy that provides the flexibility needed to network changes, such as during post-stroke recovery (Sanes and Donoghue, 2000). For example, the rostral forelimb area is considered the putative premotor area in the rodent and is involved in post-stroke reorganization of motor representations (Neafsey and Sievert, 1982; Dancause, 2006; Dancause et al., 2015; Touvykine et al., 2016). This reorganization is tailored by thalamo-cortical loops, which are the building blocks of a homeostatic and functional movement network.

\section{Input Stage: Thalamo-Cortico-Thalamic and Thalamo-Cortico-Striatal Loops}

At the input stage cortical principal cells receive, but also send information to the thalamus, integrating a redundant system that integrates sensory and motor signals (Haber and Calzavara, 2009; Leyva-Díaz and López-Bendito, 2013). Thalamo-cortical pathways receive higher-order information - already processed by other cortical or extra-cortical regions (Castro-Alamancos and Connors, 1997). For example, thalamo-cortical projections from the basal ganglia terminate in cortical layers I/II, III/IV, and V (McFarland and Haber, 2002); but also from the sensory periphery that projects sparsely to layers V and I (CastroAlamancos and Connors, 1997). Cortico-thalamic axons are formed by corticofugal pyramidal neurons located in the cortical layer VI, and to a smaller extent layer V (Donoghue and Kitai, 1981; Leyva-Díaz and López-Bendito, 2013) (except where noted, corticofugal, hereafter refers to cortical projections to descending pathways). Interestingly, cortico-thalamic neurons send information that, after relayed by the thalamus, are redirected to a different cortical region integrating different cortical areas into a global network (Leyva-Díaz and LópezBendito, 2013).

As described above, deep layer cortical neurons send projections to thalamus, and thalamus projects back to the striatum and to the superficial, the middle, and the deep cortical layers (layers I/II, III/IV, and V) (Paré and Smith, 1996; McFarland and Haber, 2000, 2002). Thus, projections that terminate in deep cortical layers, e.g., layer V, are likely to form thalamo-cortico-thalamic and thalamo-cortico-striatal loops (Haber and Calzavara, 2009). In other words, deep layer projections may interact with neurons that project back to 
both the thalamus and striatum. As a result, this interaction can reinforce cortico-thalamic and cortico-striatal inputs to specific cortico-basal ganglia circuits and may be involved in the development of specific learned behaviors (McFarland and Haber, 2002).

Superficial cortical layers I/II also receive thalamo-cortical inputs and can control the activity of any neuron with apical dendrite ascending to layer I (Haber and Calzavara, 2009). Interestingly, due to the more widespread thalamo-cortical terminals in layer I, this input can affect adjacent cortical populations and cortico-cortical connections. Thereby, potentially modulating a different loop at a different cortical region (Haber and Calzavara, 2009). This type of plasticity can be of particular interest during stroke recovery and for compensatory relearning mechanisms. Given that after a cortical ischemia the infarct core is surrounded by functional tissue, it is likely that the surviving tissue can share some of the specific striatal-thalamo-cortical projections with the lesioned tissue. Thus, superficial cortical layers would participate of thalamo-cortico-thalamic and thalamo-cortico-striatal loops that would reinforce new connections during stroke recovery and compensatory relearning of motor tasks (Haber and Calzavara, 2009; Shmuelof and Krakauer, 2011).

In other words, in the rodent agranular motor cortex, asymmetrical thalamic projections target layers I, II/III and $\mathrm{V}$ (from basal-ganglia) and layers II/III and V (from cerebellum) (reviewed in Peters et al., 2017). Stroke disrupts these thalamic targets but, the above-mentioned (1) widespread of thalamo-cortical inputs to superficial layers may affect adjacent spared cortical tissue. (2) Superficial layers may act as a preamplifier-like network, which captures these thalamic signals and drives output neurons in lower layers (Weiler et al., 2008). (3) Abundant cortico-cortical communication may affect adjacent and relevant cortical functional columns and integrate the process of augmented responses in deep layers supplemented by $(4,5)$ compensatory cortical, thalamic and striatal regions. These afferents projecting to layer $\mathrm{V}$ may initiate a sequence of synaptic and intrinsic membranedependent events, which prime the cortical network and lead to an augmented response due to heightened neuronal excitability in layer $\mathrm{V}$ and may favor compensatory relearning of movements (further explored in section "Endogenous Plasticity Mechanisms: Use-Dependent Plasticity, Augmented Responses and Neuromodulation"; Castro-Alamancos and Connors, 1996a) (Figure 1).

It is important to consider a few drawbacks of the layer specificity described here. First, that the existence of a layer IV in the rodent motor cortex is still under discussion and can be referred as the deep layer III or the superficial layer Va (Kaneko, 2013; Yamawaki et al., 2014). Second, it has been recently suggested that future studies should focus on specific circuits defined by functional cell type composition rather than the common oversimplification of laminar distribution (Guy and Staiger, 2017). Nevertheless, at the input level an abundant literature supports the importance of lamina-specific activity changes for motor learning (reviewed in Peters et al., 2017). Future studies should take advantage of the recent methods to reveal cell types and their changed post-stroke connectivity, with impact to novel stroke recovery mechanisms focused on compensatory relearning (similarly to striatal microcircuitry; Silberberg and Bolam, 2015).

\section{Output Stage: Redundancy and Intra-Circuit Connectivity}

The output cells of the cerebral cortex are the pyramidal cells $(70-80 \%$ of cortical neurons; Feldman, 1984). Their processing of sensorimotor inputs is beyond a simple output signal to descending motor neurons. The descending corticofugal pathway is complex with several intra- and extra-cortical collaterals and distinct terminations (Donoghue and Kitai, 1981). Primary projections are directed to the spinal cord, with secondary collaterals to the striatum, red nucleus, caudal pons and medulla (Donoghue and Kitai, 1981; Reiner et al., 2003; Leyva-Díaz and López-Bendito, 2013).

Pyramidal cells also show remarkable intra-circuit connectivity - intra-cortical synapses account for $\approx 70 \%$ of total synapses onto pyramidal cells (Amitai and Connors, 1995), both intra-layer (layer V; Markram et al., 1997) and inter-layers (layers II-V or VI-IV; Lund et al., 1993). Corticocortical connections are either within the same hemisphere (ipsilateral cortico-cortical connections) or from the opposite hemisphere (callosal connections) (Leyva-Díaz and LópezBendito, 2013). In rodents callosal pyramidal neurons are mainly at cortical layers II/III/IV $(\approx 80 \%)$, layer V $(\approx 20 \%)$ and, to a lesser extent, layer VI (Leyva-Díaz and López-Bendito, 2013). In addition, a population of layer $\mathrm{V}$ medium-sized pyramidal neurons is of cortico-striatal neurons that cross to the contralateral hemisphere (crossed cortico-striatal neurons; Wilson, 1987; Lévesque et al., 1996; Anderson et al., 2010).

The interconnection between hemispheres can lead to shortand long-term motor plasticity. The activation of motor neurons in the contralesional hemisphere can induce activation of cortico-cortical callosal projections to the ipsilesional hemisphere - in the same functional cortical column. For example, neurons from the contralesional caudal forelimb area can prime neurons in the spared ipsilesional caudal forelimb area (e.g., periinfarct region) (Castro-Alamancos and Connors, 1996a). Indeed, callosal cortico-cortical neurons extend axons to mirrorimage locations in the same functional area at the contralateral hemisphere (bilateral integration of information; Greig et al., 2013). Ipsilesional neurons would also undergo plastic changes modulated by the newly formed cortico-striatal connections (crossed cortico-striatal neurons; Cheng et al., 1998) during rehabilitation.

In brief, at the output stage pyramidal cells integrate a complex cortical network to produce movement. Including abundant connections with the contralateral hemisphere. Plastic changes of callosal connections is thought as a mechanism underlying the physiological reorganization in the contralesional hemisphere following stroke (Dancause, 2006). In many ways the cortical 


\section{- Physiological pathways \\ - Compensatory from Thalamus I \\ - Compensatory from Thalamus II \\ - Compensatory from Cortex I to Thalamus/Striatum II \\ .... Contralesional compensatory pathways}

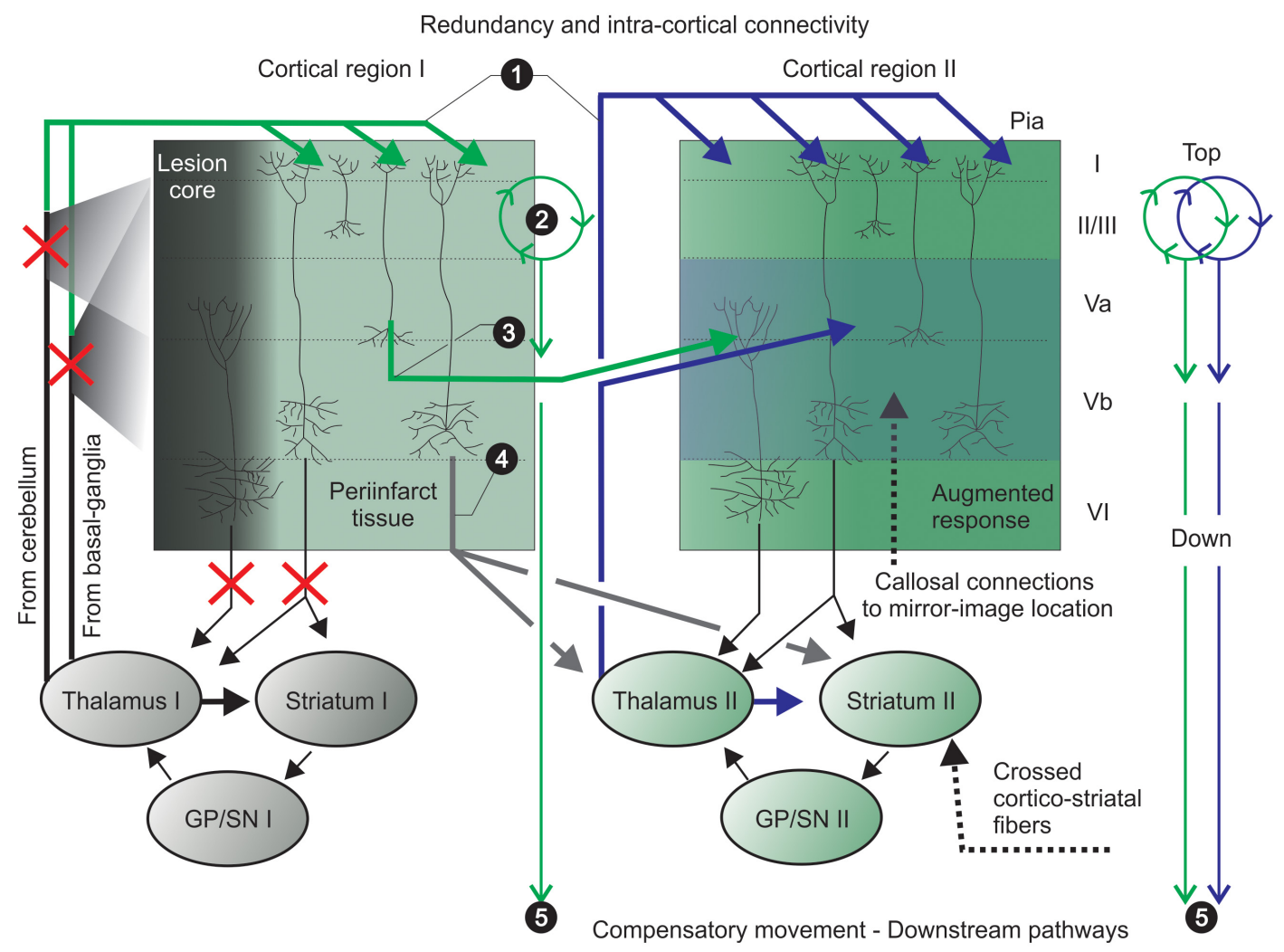

FIGURE 1 | Pronounced intra-cortical connectivity and redundancy are remarkable features of the motor cortex. Motor cortex caudal (e.g., cortical region I) and rostral (e.g., cortical region II) forelimb areas contain the primary motor neurons that encode motor map representations of forelimb skilled movements. Pyramidal neurons project to brainstem and spinal cord (not shown) and send collaterals to striatum and thalamus - integrating thalamo-cortico-thalamic and thalamo-cortico striatal loops. (1) widespread thalamo-cortical connections common to both cortical regions (I and II) target superficial layers and reach damaged, periinfarct and spared areas (upper green and blue solid lines); (2) the preamplifier-like network (green circular loop) captures thalamic I signals and drives output neurons in lower layers (Weiler et al., 2008); (3) horizontal cortico-cortical connections of neurons receive and retransmit this indirect thalamic information (previously shared with the infarct core area) (green solid lines); (4) cortico-thalamic and cortico-striatal projections (from cortical region I to II; gray solid line) integrate another striatal-thalamo-cortical loop (cortical region II). The putative participation of crossed cortico-striatal and cortico-cortical fibers is shown (hashed black lines, bottom right). (5) Cells from adjacent/spared tissue (cortical region II) share thalamo-cortical inputs with interconnected/intertwined thalamo-cortical circuits of the stroke-disrupted network to control compensatory relearning of movements. GP, globus pallidus; SN, substantia nigra.

circuitry is built with redundancy, this allows compensation by spared regions when a lesion occurs.

\section{Endogenous Plasticity Mechanisms: Use-Dependent Plasticity, Augmented Responses and Neuromodulation}

Use-dependent plasticity plays a pivotal role on post-stroke functional recovery and on motor learning (Nudo et al., 1996b; Nudo et al., 1996a). For example, potentiation of thalamo- and cortico-cortical afferents by high frequency stimulation of the corpus callosum induces cortical LTP (Chapman et al., 1998) and increases forelimb motor representations, branch complexity, dendritic length and spine density in layer V (Monfils et al., 2004). In the motor cortex the induction of LTP is only possible with partial blockage of cortical GABA $\mathrm{A}_{\mathrm{A}}$ (Castro-Alamancos and Borrell, 1995). Suggesting that a fine tuning between excitation and inhibition is paramount to motor cortex use-dependent plasticity.

Under physiological conditions a strong glutamatergic afferent input from the motor thalamus innervates cortical pyramidal neurons (mainly layer V) (Amitai, 2001; Haber and Calzavara, 2009; Kuramoto et al., 2009). As aforementioned, these projections initiate a sequence of synaptic and intrinsic membrane-dependent events that prime the cortical network and induce an augmented response, i.e., heightened neuronal excitability (Castro-Alamancos and Connors, 1996a,c) (see Figure 1 - layer $\mathrm{V}$ augmented response). Interestingly, this augmented response of layer $\mathrm{V}$ is blocked by active exploration or skilled behavioral performance and induced by inactive 
behavioral states (Castro-Alamancos and Connors, 1996b). Suggesting a dynamic modulation of short-term thalamocortical plasticity, which can occur during and after motor skill relearning (Biane et al., 2016). Given that the spread of the augmenting response to upper cortical layers depends of synaptic interconnections and active dendritic conductance (Castro-Alamancos and Connors, 1996a), it is likely that after stroke the more permissive environment (Carmichael et al., 2005; Murphy and Corbett, 2009) could favor this short-term plasticity through horizontal pathways of layers II/III in M1 (Hess et al., 1996), reaching adjacent cortical tissue (e.g., cortical region II Figure 1).

In brief, stroke recovery depends on cortical plasticity and this neuroplasticity is likely to require exploration of spared movements by the striatum (Shmuelof and Krakauer, 2011). We suggest that to unveil how these cortico-thalamo-cortical loops act on neuroplasticity mechanisms, a better understanding of the in vivo interactions during compensatory relearning is necessary. Previous evidence of where these changes occur are abundant, for example skilled training increase: dendritic length and arborization in layer II/III and V motor neurons (Greenough et al., 1985; Withers and Greenough, 1989; Kolb et al., 2008); number of synapses per neuron in layer $\mathrm{V}$ (hemisphere contralateral to the trained paw) (Kleim et al., 2004); dendritic arborization of cortical layer $\mathrm{V}$ in the contralesional motor cortex (Biernaskie and Corbett, 2001). The bulk of these findings suggests that callosal cortico-cortical, crossed corticostriatal, and ipsilateral (uncrossed corticospinal projections; Vahlsing and Feringa, 1980) projections undergo neuroplasticity changes related to compensatory relearning of motor tasks.

\section{Neuromodulation}

Different types of metabotropic glutamate receptors (mGluRs)

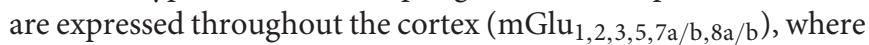
$\mathrm{mGlu}_{5} \mathrm{R}$ has the strongest expression (Shigemoto and Mizuno, 2000; Ferraguti and Shigemoto, 2006) (Figure 2A); intense expression of $\mathrm{mGlu}_{5} \mathrm{R}$ was also detected in cortical GABAergic interneurons (Kerner et al., 1997). mGluRs provide a mechanism by which adjustments of fine-tune activity occurs at the same synapses of fast glutamatergic synaptic responses (Conn and Pin, 1997). Activation of $\mathrm{mGlu}_{5}$ Rs can increase NMDA-evoked responses in the cortical tissue and, for example, $\mathrm{mGlu}_{5} \mathrm{Rs}$ antagonism can enhance MK-801 impairments of instrumental learning (Homayoun et al., 2004).

Cortical neurons also express several serotonin (5-HT)

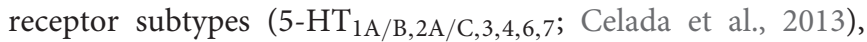
for example, cortical $5-\mathrm{HT}_{1 \mathrm{~A}}$ Rs have high mRNA expression in cortical layers V and VI (Pompeiano et al., 1992; Puig et al., 2005; Singh and Staines, 2015) (Figure 2B). It is suggested that 5-HT modulation of motor cortex excitability leans toward facilitation (Singh and Staines, 2015). Interestingly, cortical 5$\mathrm{HT}_{1 \mathrm{~A}}$ Rs activation has an overall excitatory effect on the neural networks that give rise to movement representations (Scullion et al., 2013). Selective serotonin reuptake inhibition improves learning and motor outcomes in animal models of ischemic stroke at different tasks, e.g., rotarod, staircase reaching, cylinder test, adhesive label test (McCann et al., 2014).
Another important cortical neuromodulator is acetylcholine (ACh), which can exert multiple effects on cortical neurons depending on type of target cell, pre- or post-synaptic receptor localization and receptor subtype (Wada et al., 1989, 1990; McGehee et al., 1995; Porter et al., 1999); resulting in a very complex modulation (Lucas-Meunier et al., 2003). Due to its diffuse cortical innervation some authors suggest a modulating rather than direct/synaptic role of $\mathrm{ACh}$ on the activity of the cortical circuitry (Lucas-Meunier et al., 2003 for references). Two major classes of ACh receptors are present in the rat cortex: muscarinic receptors (MRs) and nicotinic receptors. In the adult rat brain, cortical MRs subtypes are: $\mathrm{m}_{1}(26.4 \%), \mathrm{m}_{2}(21.4 \%), \mathrm{m}_{3}(7.7 \%), \mathrm{m}_{4}(44.2 \%)$, and $\mathrm{m}_{5}$ $(<1 \%)$ (Tice et al., 1996); in addition, ACh MRs are located at all cortical layers (Cortés and Palacios, 1986; Frey and Howland, 1992) and are metabotropic (Lucas-Meunier et al., 2003) (Figure 2C). Although there is a dense presence of cortical cholinergic receptors, the role of $\mathrm{ACh}$ on motor learning is still relatively underexplored. Conner's group pioneer research showed that the basal forebrain cholinergic system is essential for cortical plasticity associated with motor learning (Conner et al., 2003). Later, they showed that cholinergic mechanisms are essential for cortical map plasticity after a skilled motor training (Ramanathan et al., 2009); and that cholinergic activation within the motor cortex modulates cortical map plasticity and motor learning (Conner et al., 2010). Interestingly, the basal forebrain cholinergic system is required for successful post-stroke rehabilitation, with direct impact on cell morphology (Wang et al., 2016).

Dopamine (DA) receptors are selectively expressed in different cortical layers. Motor cortex $\mathrm{D}_{1}$ receptors are expressed at superficial (low expression; layers II-III) and deep (high expression; layers V-VI) layers (Savasta et al., 1986) (Figure 2D). $\mathrm{D}_{2}$-receptors are expressed in cortical pyramidal layer $\mathrm{V}$ but at a lower extent when compared to $\mathrm{D}_{1}$ expression (Ariano et al., 1993; Awenowicz and Porter, 2002) (Figure 2E). D $\mathrm{D}_{1}$ mRNA is present in cortico-cortical, cortico-thalamic and cortico-striatal neurons and $\mathrm{D}_{2}$ mRNA is restricted to layer $\mathrm{V}$ of corticostriatal and cortico-cortical neurons (Gaspar et al., 1995). The overall effect of DA on cortical pyramidal cell excitability may depend on phasic changes in DA concentration and GABAergic inhibition tone (Gulledge and Jaffe, 2001). $\mathrm{D}_{1} / \mathrm{D}_{2}$ dopamine receptors activation is necessary for successful motor skill learning (Hosp et al., 2011). And the integrity of the dopaminergic mesencephalic-M1 pathway is also fundamental for motor learning in rats (Hosp and Luft, 2013). Suggesting that the M1 dopaminergic system is paramount to motor skill learning. DA system is also involved on cortical motor map representations (Brown et al., 2009, 2011), movement generation (Parr-Brownlie and Hyland, 2005) and LTP-like plasticity (Korchounov and Ziemann, 2011). Thus, DA has an important role on the modulation of intra-cortical excitability to enhance plasticity and to promote motor skill learning and execution.

Finally, adrenoceptors (ARs) are most present in cortical

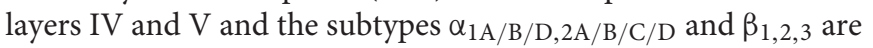
found in the cortical tissue (Wang and McCormick, 1993) 
A

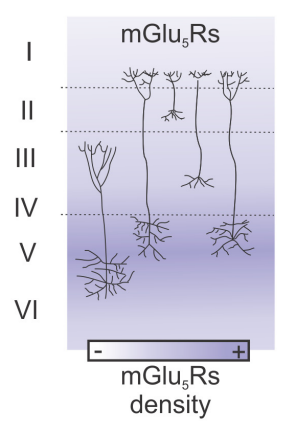

B

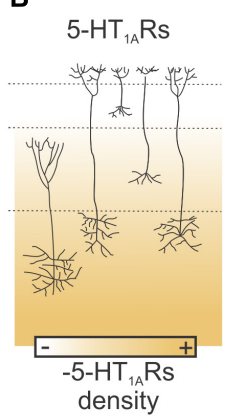

C

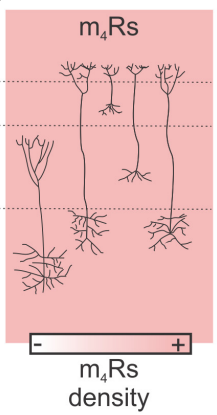

D

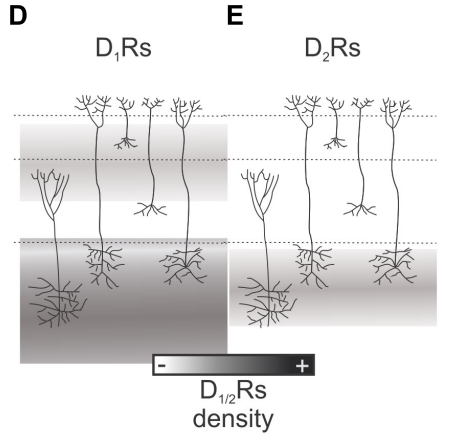

$\mathbf{F}$

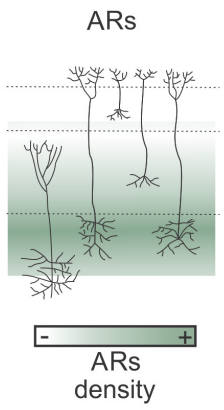

G

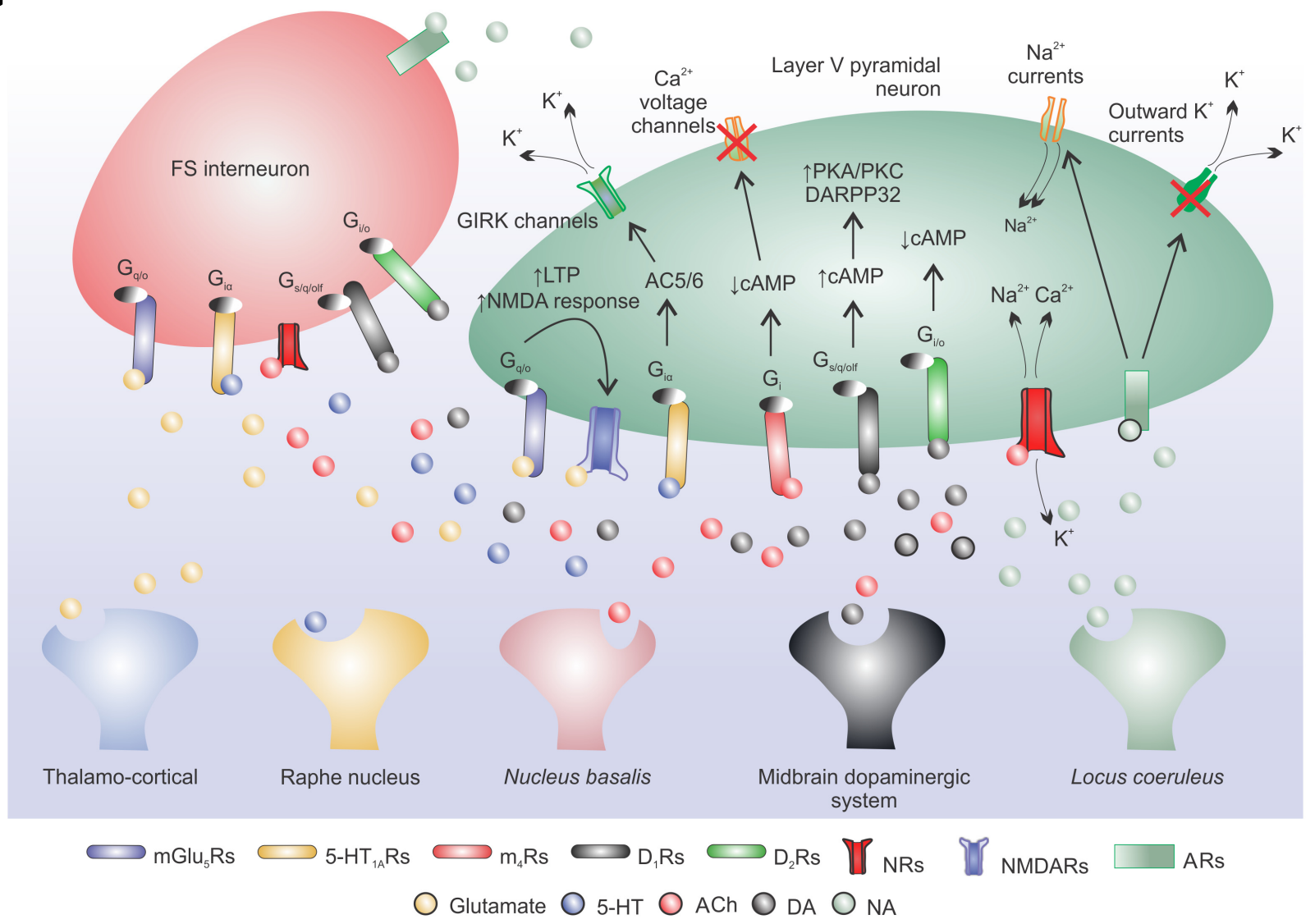

FIGURE 2 | Neuromodulation: main cortical neurotransmitter systems involved in motor learning. (A) Glutamate release from cortical or thalamic afferents can modulate cellular excitability and short/long-term plasticity in cortical pyramidal neurons. Metabotropic glutamate receptors (mGlus Rs) are mainly expressed in cortical layer $V$ and act via $G_{q / O}$ protein on downstream targets. This interaction can enhance NMDARs activity and induce LTP in pyramidal neurons. (B) Raphe nucleus serotonin (5-HT) can bind to 5- $\mathrm{HT}_{1 \mathrm{~A}} \mathrm{Rs}$ (high mRNA expression in cortical layers $\mathrm{V}$ and $\mathrm{VI}$ ) and via a $\mathrm{G}_{\mathrm{i} \alpha}$ protein-AC5/6 pathway induce $\mathrm{K}^{+}$efflux leading to cell hyperpolarization, both in pyramidal cells and FS interneurons. (C) Nucleus basalis acetylcholine (ACh) binds to muscarinic receptors (MRs; e.g., $m_{4}$ Rs) or nicotinic receptors (NRs). $m_{4} R s$ are expressed in all cortical layers and are coupled to $G_{i}$ proteins that can reduce cellular activity through cAMP signaling. NMDARs are permeable to $\mathrm{Na}^{+}, \mathrm{K}^{+}$, and $\mathrm{Ca}^{2+}$ ions and are modulated by intra- and extra-Ca $\mathrm{Ca}^{2+}$ concentrations (not shown). (D,E) Dopamine (DA) released by the midbrain dopaminergic system can bind to $D_{1} R s$ (low expression in layers II-III and high expression in layers $V-V I$ ) or $D_{2} R s$ (expressed in layer $V$ but at a lower extent when compared to $D_{1}$ expression) and increase or decrease cellular excitability, respectively, via cAMP acting on downstream targets (e.g., DARPP32). (F) Locus coeruleus noradrenaline (NA) released to the cerebral cortex binds to adrenoceptors (ARs) highly expressed in cortical layers IV and V. NA may increase cortical excitability via a reduction of outward $\mathrm{K}^{+}$currents and increase of $\mathrm{Na}^{+}$currents. (G) Simplified model of cortical neurotransmitter systems involved in motor learning.

(Figure 2F). Overall, noradrenaline (NA) increases the excitability of cortical pyramidal cells, but also the activity of cortical GABAergic non-pyramidal cells
(Kawaguchi and Shindou, 1998). In the motor cortex, blockade of NA receptors suppresses the induction of LTP-like plasticity (Korchounov and Ziemann, 2011). Figure 2G shows a simplified 
model of cortical neurotransmitter systems involved in motor learning.

\section{THE STRIATAL CIRCUIT}

The striatum is the main input nucleus of the basal ganglia and is a single structure in rodents. In rodents, striatal dorsolateral and medial portions are equivalent to putamen and caudate in primates, respectively (Heilbronner et al., 2016). The striatum can be divided in two compartments based on neurochemical characteristics and connections: patch ( $\mu$ opiate receptor, substance $\mathrm{P}$ and enkephalin) and matrix (ACh esterase and calcium binding protein) (for references see Johnston et al., 1990; Gerfen, 1992; Lopez-Huerta et al., 2016). Anatomically, patch is a structure of interconnected tubes with finger-like branches and matrix is composed of well demarcated "dots" or "islands" of moderate to strong DA fluorescence (Olson et al., 1972; Johnston et al., 1990; Lopez-Huerta et al., 2016). Another recently added compartment is the annular compartment, which surrounds the striosome (or patch) (Brimblecombe and Cragg, 2015; Perrin and Venance, 2019). Matrix contains both direct and indirect striatal output pathways and does not exchange synaptic information with patch cells (Lopez-Huerta et al., 2016). Neurons of the matrix compartment make up about $85 \%$ of striatal volume (Johnston et al., 1990), contain the main outputs to globus pallidus and substantia nigra and are suggested to participate in behaviors associated with striatal and cortico-striatal function, such as skill learning (LopezHuerta et al., 2016). The patch (or striosome) compartment comprises a maximal striatal area of $\approx 15 \%$ of the rostral striatum in adult rodents (Lança et al., 1986). Patch and matrix compartments integrate limbic and sensorimotor information, through patch and exo-patch neurons (Smith et al., 2016) (Figure 3A). This compartmentalization affects DA release among striosomes (increase), annular compartment (decrease), and matrix (unmodified) (Brimblecombe and Cragg, 2015; Salinas et al., 2016; Perrin and Venance, 2019). In addition, cannabinoid receptor type $1\left(\mathrm{CB}_{1} \mathrm{R}\right)$ protein displays elevated expression in striosomes relative to the surrounding matrix (Davis et al., 2018). This complex striatal system is involved in motor skill learning in a medial (early skill learning) to lateral (late skill learning) gradient (Yin et al., 2009) (Figure 3A).

\section{Input Stage}

The striatum is the input structure of the basal ganglia network. Cortical and thalamic glutamatergic signals converge into the striatum and are modulated by dopaminergic signals from mesolimbic nuclei (for references see Calabresi et al., 1996; Cerovic et al., 2013). In rodents, while cortico-striatal afferents are from several cortical regions, thalamo-striatal afferents are mainly from the parafascicular thalamic nucleus (Calabresi et al., 1996; Smith et al., 2014). Thalamo-striatal afferents have been implicated in controlling presynaptic suppression of cortico-striatal inputs through cholinergic interneurons, with implications on attentional shifts and cessation of ongoing motor programs (Ding et al., 2010). Recently, GABAergic inputs from the motor cortex to the dorsal striatum were described and implicated in motor control (Melzer et al., 2017). Optogenetic stimulation of these GABAergic long-range projections, such as $\mathrm{M} 1$ parvalbumin $(\mathrm{PV})^{+}$and $\mathrm{M} 2$ somatostatin $(\mathrm{SOM})^{+}$, reduced locomotion (Melzer et al., 2017). These above-mentioned examples challenge the view of how thalamo- and cortico-striatal projections can modulate motor behavior and motor learning. Interestingly, post-stroke changes of cortical inhibitory markers, such as periinfarct $\mathrm{PV}^{+}$and $\mathrm{SOM}^{+}$have been reported (Zeiler et al., 2013; Alia et al., 2016; Spalletti et al., 2017), suggesting a role of this novel pathway for stroke recovery.

The majority of striatal cellular content is of GABAergic projection neurons, medium spiny neurons (MSNs), which are $\approx 95 \%$ of all neurons in the rat striatum (Kemp and Powell, 1971; Gerfen, 1992; Tepper et al., 2007; Kreitzer, 2009). The remaining glutamatergic afferents target intrastriatal interneurons: large cholinergic aspiny neurons (or cholinergic tonically active neurons), GABAergic $\mathrm{PV}^{+}$or neuropeptide $\mathrm{Y}^{+} / \mathrm{SOM}^{+}$interneurons (Tepper et al., 2004; for reviews and references see Kreitzer, 2009; Lovinger, 2010).

Cholinergic interneurons are only $\approx 1 \%$ of striatal cells, but their influence is significant due to large cell bodies and widespread axonal connections with MSNs. They receive scattered excitatory innervation mainly from thalamus and to a lesser extent from cortex, and inhibitory synapses from MSNs (Kreitzer, 2009 for references). Striatal cholinergic neurons may regulate functions of motor behavior and can release $\mathrm{ACh}$, or can also co-release glutamate with ACh (Lim et al., 2014).

Motor cortex cortico-striatal afferents to patch and matrix compartments are mostly from layer $\mathrm{V}$ and to a lesser extent from layers II/III and VI (Smith et al., 2016). Differences in innervation of patch and matrix by cortical layers were reported, where patch and matrix compartments would receive corticostriatal projections mostly from layers V/VI and superficial layer V and layer II/III, respectively (Gerfen, 1989). Later, the somatosensory cortex was considered to project exclusively to the matrix compartment, and layers $\mathrm{Vb}-\mathrm{VI}$ preferentially to patches whereas layers III-Va to matrix axons (Kincaid and Wilson, 1996). But recent findings using genetic-based dissection suggest that cortico-striatal connections target patch and matrix compartments equally, regardless of region. Specifically, in M1, striatal patch/matrix inputs originate at layer $\mathrm{V}(\approx 75 \%)$, at layers II/III $(\approx 10 \%)$ and at layer VI $(\approx 15 \%)$. Either striosomes (or pathes) and matrix contain MSNs from direct and indirect pathways (Cerovic et al., 2013).

\section{Output Stage: Direct and Indirect Pathways}

Activation of MSNs results in GABA release to the principal MSNs projections: external/internal globus pallidus and substantia nigra (Gerfen, 1992) (Figure 3B). The striatal cellular mechanisms provide a continuous balance between direct and indirect pathways. The direct pathway releases movements by disinhibiting thalamic activity and the indirect pathway restrains movements by inhibiting thalamic activity (Gerfen, 1992; Graybiel, 1995). 
A

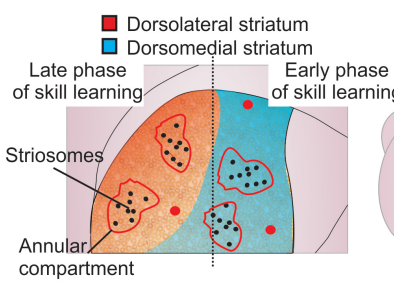

$\square$ Matrix compartment $\square$ Exo-patch cells

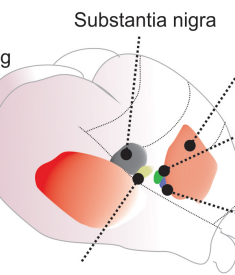

Subthalamic nucleus

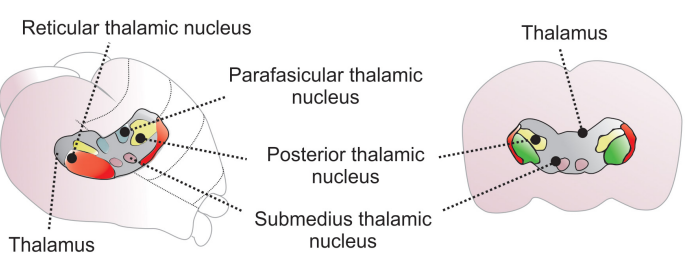

C

Long-term depression

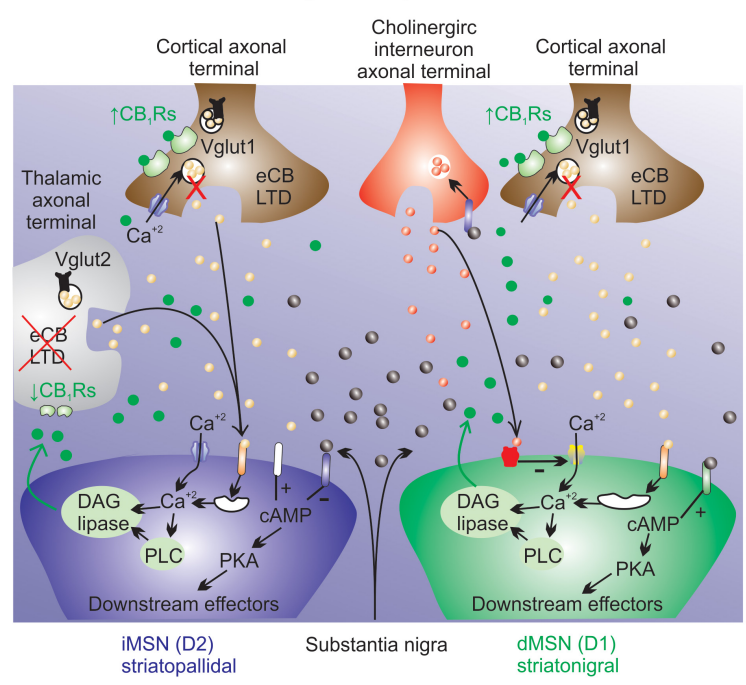

B

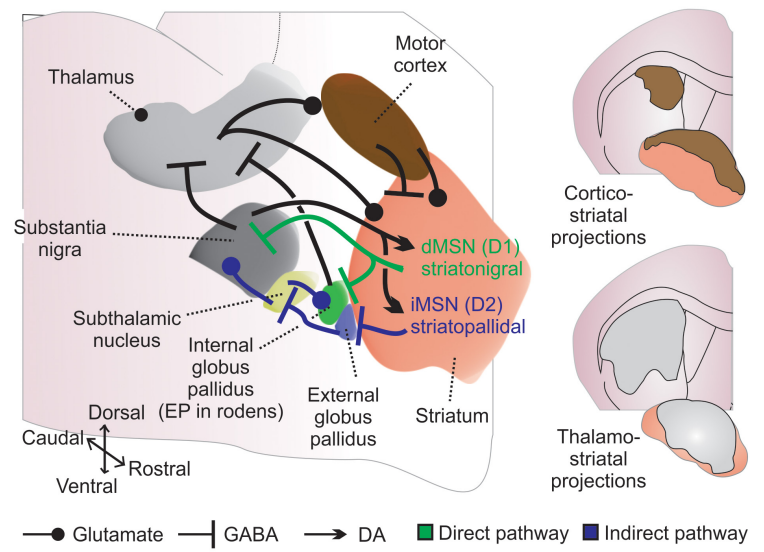

D

Long-term potentiation

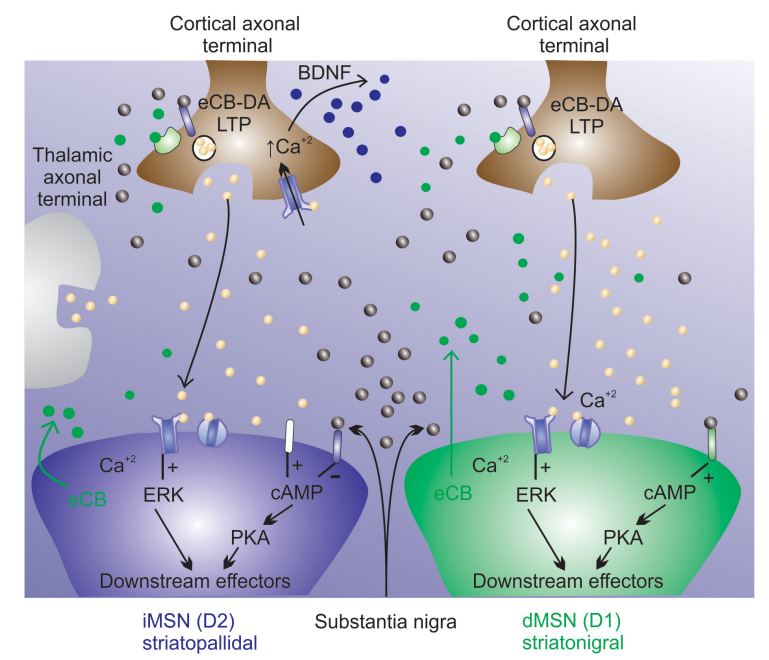

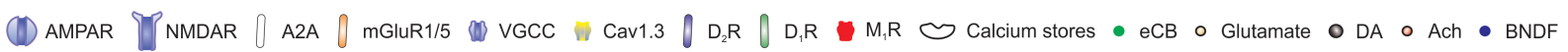

FIGURE 3 | Striatal cellular and synaptic organization. (A) Striatum is a single structure in rodents: see striatal theoretical compartmentalization into dorsolateral (red; putamen) and medial (blue; caudate) striatum (Hjornevik, 2007; Heilbronner et al., 2016). Early and late skill learning are suggested to occur in a mediolateral fashion, respectively. (A, lower panels) In rodents the main thalamo-striatal afferents originate from the parafascicular nucleus. (B) The striatal circuit is composed of several intertwined structures involved in inhibition (indirect-pathway) or disinhibition (direct-pathway) of movement. The indirect-pathway (blue arrows) is formed by striatopallidal MSNs (iMSNs) that project to GABAergic pallidal neurons (external globus pallidus), which exert a powerful inhibitory control into proximal dendrites of glutamatergic neurons in the subthalamic nucleus. Subthalamic nucleus neurons send excitatory afferents to inhibitory output neurons of substantia nigra, and also to internal globus pallidus neurons. The net effect of indirect-pathway activation is inhibition of thalamo-cortical projection neurons, which can reduce cortical premotor drive and inhibit movement. The direct-pathway circuit (green arrows) is formed by striatonigral medium spiny neurons (dMSNs) that provides mainly inhibitory inputs to both GABAergic and dopaminergic cells in substantia nigra, which in turn sends axons to motor nuclei of the thalamus. Direct-pathway activation results in disinhibition of excitatory thalamo-cortical projections, resulting in activation of cortical premotor circuits and the selection/facilitation of movement. Glutamatergic striatal inputs from all cortical areas massively converge into the striatum. Also note the long-range GABAergic projections from the motor cortex to the dorsal striatum. Cortico-striatal and thalamo-striatal glutamatergic inputs target MSNs, large cholinergic interneurons and fast spiking interneurons.

Cortico-striatal projections receive several inputs and integrate this information into striatal target neurons. Cholinergic interneurons receive scattered excitatory innervation mainly from thalamus and inhibitory synapses from MSNs. 'Up-states' are modulated by intrastriatal acetylcholine (ACh) and to strong intra-striatal DA release, $D_{1}$ Rs activation and striatal LTP. Midbrain dopaminergic terminals release dopamine (DA), which exerts a massive effect on all striatal cells. "Down-states" are associated to reduced intra-striatal DA, $D_{1} R s / D_{2} R s$ activation and striatal LTD. Striatal LTP/LTD is also dependent on NMDARs activation and Ca ${ }^{2+}$ influx in MSNs. (B, right panels) Also note the distribution of cortico-striatal and thalamo-striatal afferents (Hunnicutt et al., 2016). (C) Long-term depression is dependent on mGLU $U_{1 / 5}$ Rs, $D_{2} R s, M_{1} R s$, and $C_{1} B R s$. For example, in iMSNs, prolonged stimulation of excitatory afferents paired with post-synaptic depolarization triggers the production and release of eCBs (e.g., 2AG) from the precursor diacylglycerol (DAG) through the activation of $\mathrm{mGlu}_{1 / 5} \mathrm{Rs}_{\mathrm{s}}$ and phospholipase $\mathrm{C}$ (PLC; this process is dependent on $\mathrm{Ca}^{2+}$ ). (D) Long-term potentiation is dependent on NMDARs, $\mathrm{D}_{1} \mathrm{Rs}, \mathrm{A} 2 \mathrm{ARs}$ and CB${ }_{1}$ Rs. LTP is NMDARs dependent and is likely to involve the exocytosis of AMPA receptors. For example, LTP in the indirect pathway is negatively regulated by $D_{2}$ Rs (dependent on extracellular regulated kinase; ERK) and positively regulated by adenosine A2ARs. 
The direct-pathway circuit is formed by striatonigral MSNs (dMSNs) that provides mainly inhibitory inputs to both GABAergic and dopaminergic cells in substantia nigra, which in turn send axons to motor nuclei of the thalamus (Gerfen, 1992; Kreitzer and Malenka, 2008). Direct-pathway activation results in disinhibition of excitatory thalamo-cortical projections and activation of cortical premotor circuits to select/facilitate movement (Kreitzer and Malenka, 2008). The indirect-pathway is formed by striatopallidal MSNs (iMSNs) that projects to external globus pallidus GABAergic neurons (entopeduncular nucleus in rodents; EP); which exert a powerful inhibitory control into proximal dendrites of glutamatergic neurons in the subthalamic nucleus (Smith et al., 1990; Gerfen, 1992; Kreitzer and Malenka, 2008). Subthalamic nucleus neurons send excitatory afferents to inhibitory output neurons (i.e., substantia nigra) and the net effect of indirect-pathway activation is inhibition of thalamocortical projection neurons, which can reduce cortical premotor drive and inhibit movement (Kreitzer and Malenka, 2008) (Figure 3C). An intertwined function of both striatal pathways was recently proposed and postulated that the striatum would "filter" movement output integrating cortical glutamatergic and nigral dopaminergic inputs (Cui et al., 2013; Calabresi et al., 2014; Wang et al., 2015).

Cellular and synaptic organization is drastically changed in the striatum following stroke. It is likely that the striatal 'search' for different functional actions is accompanied by many structural changes. The bulk of the findings reviewed here supply abundant evidence of where these structural changes occur. For example, cortical lesions induce axonal sprouting in the denervated striatum (Uryu et al., 2001), dense network changes of crossed cortico-striatal projections (contralesional to ipsilesional; Napieralski et al., 1996), increased MSNs dendritic lengths (Gonzalez and Kolb, 2003), increased cortico-striatal projections and enkephalin mRNA levels (Napieralski et al., 1996; Uryu et al., 2001). Nevertheless, the post-stroke striatal 'search' task for functional actions is still poorly understood, such as how the striatal network would "filter" movement output integrating these novel and compensatory striatal plasticity, e.g., crossed cortico-striatal projections. Crossed cortico-striatal projections are only $\approx 20 \%$ of the total afferents to the contralateral striatum (Smith et al., 2016), but massive collateral sprouting from this minor projection would still be representative (Uryu et al., 2001). Interestingly, crossed cortico-striatal neurons preferentially make synapses with dMSNs, while cortico-striatal neurons with iMSNs (Cowan and Wilson, 1994; Florio et al., 2018). This suggests that the increased post-stroke crossed cortico-striatal inputs would favor movement disinhibition in the ipsilesional motor system. This can modulate excitatory outputs to thalamic neurons in the ipsilesional hemisphere that are the final pathway from the striatal system at the output level.

\section{Endogenous Plasticity Mechanisms: "Up-" and "Down-States"}

The striatum exhibits anatomo-functional complexity and intrinsic diversity, such as synaptic transmission may depend on bidirectional plasticity and spike-timing dependent plasticity
(STDP). This implies that the precise relative timing and interval between presynaptic and postsynaptic action potentials determine the strength of striatal synaptic potentiation or depression (Cerovic et al., 2013; Perrin and Venance, 2019). Albeit, the role of such type of plasticity for LTP/LTD is still under debate (Lisman and Spruston, 2010). This is a very complex subject, plasticity mechanisms are variable and depend on many factors, such as: stimulation protocol, slice preparation, interplay between receptors, among others. Here, we show a simplified view of striatal plasticity mechanisms, focused on the most recent findings that relate to motor skill learning. The striatum acts as a relay nucleus, which integrates strong cortical and thalamic inputs and retransmit information via indirect thalamic projections. As aforementioned, motor skill learning modifies striatal responses during this relay process, and these changes are suggested to occur in a medial to lateral fashion (Tepper et al., 2007; Kreitzer, 2009; Yin et al., 2009). Hence, these changes in transmission affect the activity of thalamo-cortical projections and, as a consequence, motor behavior (Fisone et al., 2007). Longlasting changes of cortico-striatal and thalamo-striatal synapses are considered to be a cellular basis of motor learning.

Striatal and thalamic reorganization following a cortical lesion are well documented. For example, Gonzalez and Kolb (2003) showed that small middle cerebral artery occlusion results in increased MSNs dendritic lengths in both hemispheres. Additionally, larger occlusions increased MSNs dendritic length in the contralesional hemisphere, but dendritic branching in the ipsilesional hemisphere (dorsolateral striatum; Gonzalez and Kolb, 2003). Interestingly, in the striatum a single EPSP from cortico-striatal glutamatergic fibers is not sufficient to depolarize MSNs to overcome the voltage-dependent $\mathrm{Mg}^{2+}$ blockade of NMDARs. But, in pathological conditions, such as stroke, a single excitatory input can lead to the activation of striatal NMDARs due to the "pathological" removal of the magnesium block (Calabresi et al., 2000 for references). Cortical ischemia also results in reduction of neurons, $\mathrm{GABA}_{\mathrm{A}}$ receptors and increase in NMDARs in the ipsilesional thalamus projecting to cortical damaged areas (Qu et al., 1998).

Thus, stroke disrupts cortico-striatal glutamatergic inputs in the damaged site, but also induces MSNs plasticity in both hemispheres. Glutamate has an important role on regulating striatal excitability, such as in response to glutamatergic synaptic input MSNs can transition to a depolarized "up state" near spike threshold. Short-term changes on "up-state" potentials involve KCNQ channels modulated by intrastriatal cholinergic interneurons. ACh binds to $\mathrm{m}_{1} \mathrm{Rs}$ in MSNs and activate KCNQ channels through PLC $\beta / \mathrm{PKC}$ pathway resulting in increased MSNs excitability (Shen et al., 2005). "Up-states" are also suggested to be linked to strong intra-striatal DA release, $D_{1}$ Rs activation and striatal LTP.

Conversely, "down-states" are associated to low intra-striatal DA, $D_{1}$ Rs $/ D_{2}$ Rs activation and striatal LTD (Calabresi et al., 1997, 2007; Shen et al., 2008). Striatal LTD reduces the activity of projecting GABAergic MSNs, and influences the output signals from the striatum to other structures that control motor activity (Calabresi et al., 1992). Skill learning and cortico-striatal LTD in the dorsolateral striatum are dependent on AC5 and CAMP 
signaling (Kheirbek et al., 2009). In addition, the generation of striatal LTD requires $\mathrm{Ca}^{2+}$ influx through voltage dependent $\mathrm{Ca}^{2+}$ channels, $\mathrm{Ca}^{2+}$-dependent protein kinases (Calabresi et al., 1994) and synthesis of endocannabinoids (eCBs) (Cerovic et al., 2013). eCB signaling integrates signals from different neurotransmitters, such as glutamate and dopamine, with voltage gated $\mathrm{Ca}^{2+}$ signals (Cerovic et al., 2013). eCB-LTD is modulated by $\mathrm{D}_{2}$ Rs and dependent on postsynaptic mGluRs activation and L-type calcium channels (Kreitzer and Malenka, 2005). Similarly glutamate-LTD is also modulated by $\mathrm{D}_{2}$ Rs. For example, after high-frequency stimulation of cortico-striatal fibers, mice lacking $\mathrm{D}_{2}$ Rs shift from the expected LTD to a NMDARs-mediated LTP (Calabresi et al., 1997). Another interesting feature of striatal eCB modulation is the differential role on cortico-striatal (high $\left[\mathrm{CB}_{1} \mathrm{Rs}\right]$ ) and thalamo-striatal (low $\left[\mathrm{CB}_{1} \mathrm{Rs}\right]$ ) afferents (Wu et al., 2015). The existence of two forms of striatal LTD induced at up- and down-states (Mathur et al., 2013) and bidirectional DA modulation of eCB-LTD expression (Cui et al., 2015, 2016; Wu et al., 2015; Xu et al., 2018), reflects the complex interactions involved in striatal action control.

Skill learning activates the cortico-striatal pathway, the glutamatergic system and complex cellular mechanisms related to NMDARs activation. In rotarod trained animals, the striatal NMDARs subunit NR1 is up-regulated (D'Amours et al., 2011) and NMDARs or NR2A blockade impairs motor learning in this task in a dose-dependent manner (Lemay-Clermont et al., 2011). Additionally, Yin et al. (2009) demonstrated the medial to lateral gradient of early and late skill learning, respectively, where LTP is observed in iMSNs at the dorsolateral striatum (late skill learning), but not at dMSNs; also that early skill learning plasticity is likely non-NMDARs dependent in the dorsomedial striatum (Yin et al., 2009). Recently, this view has been challenged by a parallel (associative: medial pre-frontal cortex and dorsomedial striatum; sensorimotor: M1 and dorsolateral striatum), but dissociable, processing in cortico-striatal inputs during skill learning (Kupferschmidt et al., 2017). Kupferschmidt et al. (2017) show parallel activity in these associative and sensorimotor circuits while mice refined rotarod performance. Additionally, thalamo-striatal NMDARs-LTD plasticity is also observed in iMSNs and dMSNs (Ding et al., 2008; Ellender et al., 2013; Wu et al., 2015), further that blocking serotonergic signaling favor spike-timing-dependent LTD in dMSNs (Cavaccini et al., 2018). Finally, that presynaptic NMDARs are also involved in corticostriatal LTP plasticity through BDNF release (Park et al., 2014), but the role of this presynaptic plasticity to stroke relearning is still underexplored. Briefly, abundant findings support the idea that skill learning experience produces changes in cortico-striatal transmission efficacy and induce the formation of sensorimotor links (see suggested reviews at the end of this section). For example, specific context-dependent patterns of cortical activity can engage selected motor programs (Mahon et al., 2004), and such changes partially depend on striatal LTP/LTD mechanisms.

State changes are also involved in striatal plasticity, such as repetitive cortico-striatal transmission during the "up-state" can overcome the threshold for NMDARs activation and, if associated with a strong release of DA, lead to LTP induction. Conversely, repetitive transmission during the "down-state," in association with low DA levels should lead to LTD (Calabresi et al., 1997, 2007; Charpier and Deniau, 1997). The circuitry of relevant motor programs would undergo plastic changes through induction of striatal LTD and LTP (Reynolds et al., 2001). Excitation of dMSNs results in the disinhibition of premotor networks, thus LTP at excitatory striatal inputs would be favorable to the initiation of movements and critical for motor learning (Charpier and Deniau, 1997; Yin et al., 2009; O'Hare et al., 2016).

Striatal cellular mechanisms involved in synaptic modulation are mainly related to presynaptic inhibition of neurotransmitter release through GPCRs (via $\mathrm{G}_{\mathrm{i} / \mathrm{o}}$ ) and eCBs (Lovinger, 2010; Cerovic et al., 2013). Cortico-striatal terminals are controlled by presynaptic receptors, when activated can result in negative feedback on the striatal release of glutamate (Calabresi et al., 1996). As aforementioned, activation of presynaptic $C_{1} B_{1} R s$ may have distinct effects on cortico-striatal and thalamostriatal axonal terminals, due to differential presynaptic $\mathrm{CB}_{1} \mathrm{R}$ expression of these inputs (Wu et al., 2015) (Figures 3C,D). Finally, it is important to mention the role of striatal fastspiking interneurons for experience-dependent behavior (O'Hare et al., 2018) and striatum-dependent sequence learning (via feedforward inhibition that restricts MSN bursting and calciumdependent synaptic plasticity) (Owen et al., 2018).

Here, we highlight the main and most up-to date striatal plasticity mechanisms. This is currently a hot topic in neuroscience and several recent reviews explore this subject in depth. For example, on how (1) dopamine neurotransmission acts in concert with several neurotransmitters to regulate cortical, thalamic and limbic excitatory inputs (Surmeier et al., 2009; Bamford et al., 2018); (2) are the complex interactions between striatal plasticity and learning (Perrin and Venance, 2019); (3) are the complex computations performed by the basal ganglia circuits (Yin, 2017); (4) to clarify the relationship between neuronal plasticity in the basal ganglia and habitual behavior (with focus in kinematics of movement; O'Hare et al., 2018); (5) eCB-DA interaction affects striatal synaptic plasticity (Mathur and Lovinger, 2012); (6) genetic tools enabled new experimental protocols to reveal striatal cell types and connectivity (Silberberg and Bolam, 2015); (7) the thalamo-striatal system changes in diseased states (Smith et al., 2014). Perrin and Venance (2019) suggest that a new period of abundant and constructive debates is opened in the field of striatal plasticity. We suggest that the poststroke recovery field should take advantage of this fruitful period to establish new mechanisms and therapies for stroke recovery.

\section{TWO PHASES OF STROKE RECOVERY - 'FAST' AND 'SLOW' MOTOR RELEARNING}

Cortical and striatal circuits work together during the development of motor skills characterized in two phases. A 'fast' improvement of motor performance with rapid behavioral outcomes, which can be observed both within a single training session and across the first few sessions. And a 'slow' improvement that develops across sessions, with more moderate 
gains in performance that progress across multiple training sessions (Karni et al., 1998; Kleim et al., 2004). During 'fast' motor learning cortical and striatal circuits undergo rapid and extensive recruitment with parallel activity; conversely, during 'slow' learning the activity patterns differs between structures (Costa et al., 2004). This suggests that both structures work to rapidly adapt the motor system to the new task. During 'slow' learning parallel recruitment is less often and cortical or striatal recruitment are likely associated to distinct movement features (Costa et al., 2004).

In the same line of thoughts, cortical motor representation changes do not contribute to the initial acquisition of motor skills - but represent the consolidation of motor skills that occur during the later 'slow' phase of learning (Kleim et al., 1998; Kleim et al., 2004; Krakauer and Shadmehr, 2006). This suggests that 'fast' skill improvement is related to an ongoing process, not yet consolidated intra-cortically, thus dependent on parallel striatal activity. For example, post-stroke relearning could activate a large number of cortical cells during initial stages, but with practice increase the number of cells active that correlate with the motor task (as for motor learning; Peters et al., 2014; Makino et al., 2016). This would translate in a functional motor map/engram if sufficient reinforcement of motor action render behavior habitual (Hosp and Luft, 2011).

In other words, if during this striatal 'search' task the rewiring does not elicit functional movements, the rewardrelated reinforcement is poor. Hence, this dysfunctional motor map should not consolidate and the striatal 'search' should continue. Recovery would rely on this parallel cortico-striatal processing until permanent and relevant changes are reinforced and stored intra-cortically. In search for spared/functional movements the striatal network attempts to integrate the remaining pieces of cortico-thalamic network. Callosal corticocortical connections from the contralesional homotopic motor cortex and crossed cortico-striatal connections help to direct and guide this changing network - in search for functional movements. In addition, thalamo-cortical loops relayed by the striatum have the flexibility needed for adaptation to imposed behavioral demands following motor skill training (Biane et al., 2016). Striatal 'up' and 'down' states modulated by changed glutamatergic inputs - in some regions reduced (lesion) and in others increased (compensatory connections), redirects information flow throughout the circuits. Hebbian plasticity in the associated population of cells may change synaptic strengths to favor plasticity of pathways coincidently active and eventually results in a refined ensemble and stereotyped functional behavior (Makino et al., 2016). Thus, remainings of previous loops that are disrupted by the lesion can join this novel network assisted by intense corticostriatal parallel processing - a novel cortical representation is later formed. This idea is supported by recent findings on how optogenetic rewiring of thalamo-cortical circuits can restore function in the stroke injured brain (Tennant et al., 2017). Rehabilitation would offer the repeated opportunity to explore, select and refine impaired movements (Makino et al., 2016).
Interestingly, post-stroke, a relatively 'fast' behavioral motor recovery is followed by a plateau of 'slow' or absent recovery (62-70\% proportional to the initial impairment; Jeffers et al., 2018). Rehabilitation is thought to help guidance and pruning of new connections, which due widespread activation of growth and plasticity mechanisms following the lesion may form unbalanced, non-functional connections (Murphy and Corbett, 2009). This would fit perfectly with the striatal 'search task' during relearning, adding specificity and homeostatic balance to novel functional connections. Indeed, early onset of rehabilitation during this 'fast' period consistently results in better functional outcomes (Biernaskie et al., 2004; Murphy and Corbett, 2009).

At chronic phases of 'slow' motor recovery the motor circuits would constantly modify to select and refine novel skills. How this process occurs is still unclear, it is likely that the 'fast' attempt to recover function involves the old cortical/striatal circuits, or what is left of it. It is reasonable to think that this is a less demanding homeostatic adaptation, compared to novel long-distance connections and changes of regions remote from the lesion - previously minimally involved in the motor skill.

Indeed, facilitation of LTP (1 week; Hagemann et al., 1998) and use-dependent neuronal activation (10 days; Clarke et al., 2014) in the dysfunctional perilesional cortex occur early after stroke and may indicate 'fast' changes of function in this region. Such changes are absent in homotopic contralateral areas at this early time point (Hagemann et al., 1998; Clarke et al., 2014). In chronic post-stroke, reorganization of functional circuits of parallel projecting cortical areas in the ipsilesional and contralesional hemispheres suggests that long-term or 'slow' reorganizational changes involve undamaged regions adjacent and distant to the lesion core (3-4 weeks; squirrel monkeys; Nudo et al., 1996b, 2001). Examples of such 'slow' changes include: damaged ipsilesional cortico-striatal connections that are functionally 'replaced' by increased crossed cortico-striatal projections to the denervated striatum (Cheng et al., 1998); axonal sprouting in the contralesional striatum (Uryu et al., 2001) that may be linked to increased crossed cortico-striatal projections (ipsilateral to contralateral; Napieralski et al., 1996; Uryu et al., 2001). These processes would slowly evolve during relearning of movements through striatal exploration, selection and refinement of functional movements. We suggest that these features would be part of a 'slow' compensatory relearning mechanism by which the motor function would be restored (Figure 4).

\section{Are Cortical Motor Maps a Reflection of Consolidation?}

Here we discuss how the motor map may reflect consolidationreconsolidation processes. If the motor map is a reflection of consolidation of motor memories it should stabilize and persist over time. Evidence, both in humans (Ward et al., 2003; Tombari et al., 2004) and rodents (Molina-Luna et al., 2008; Reed et al., 2011), indicates that this is indeed not the case. According to the expansion-renormalization theory, learning-related neural processes often follow the sequence of 


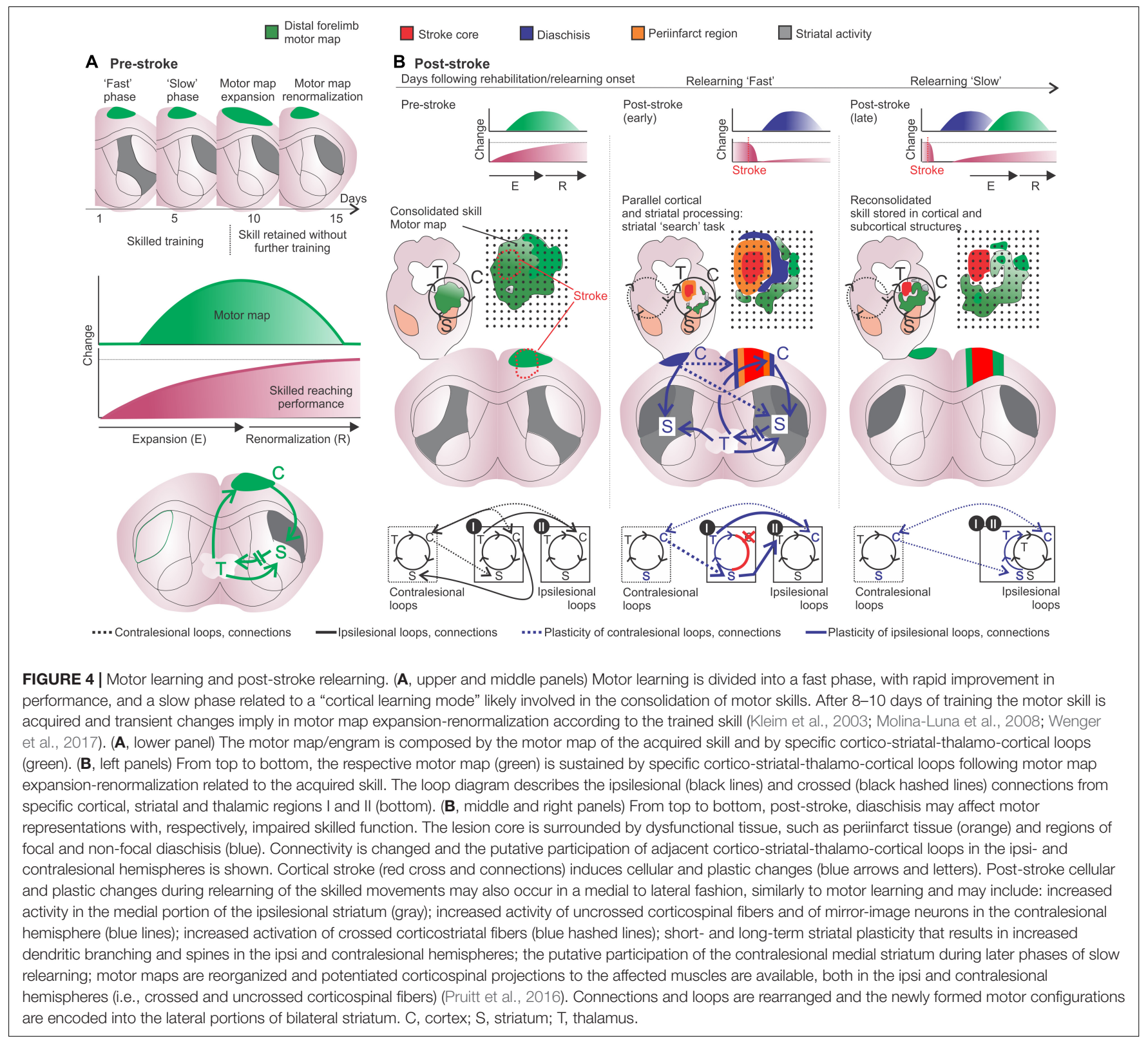

expansion, selection and renormalization (reviewed in Wenger et al., 2017). Motor map expansion may be thought as a transitory "cortical learning mode", which according to the expansionrenormalization model should subsequently refine and compact, maintaining the readiness of the learned skill (Molina-Luna et al., 2008; Wenger et al., 2017). It is reasonable to think that following motor skill learning prolonged map expansion may reduce the flexibility needed to acquire subsequent novel motor skills.

Nevertheless, several studies indicate that the motor map may encompass some features of consolidated motor memories, such as synaptogenesis (Kleim et al., 2004), susceptibility to protein synthesis inhibition (anisomycin, ANI; Kleim et al., 2003), dependence of DA (following intrastriatal 6hydroxydopamine injections; Brown et al., 2009 - also see
Hosp and Luft, 2013) and influence of cholinergic (Conner et al., 2005; Ramanathan et al., 2009) and serotonergic (Scullion et al., 2013) mechanisms. It is also the case of post-stroke motor maps, rehabilitative training may drive the reemergence and reorganization of motor maps (Nudo et al., 1996b; Conner et al., 2005; Ramanathan et al., 2006) and infusion of ANI can decrease the reorganized motor map, synaptic density and post-stroke performance improvement (Kim et al., 2018).

Similarly, studies support the role of the motor cortex for skilled behavior (Guo et al., 2015; Miri et al., 2017; Galiñanes et al., 2018), for motor learning (Peters et al., 2014) and of the somatosensory cortex for motor memory update and motor adaptation (Mathis et al., 2017). Conversely, evidence also indicates that non-dexterous motor performance is not 
dependent on the motor cortex (Kawai et al., 2015; Miri et al., 2017; also see Papale and Hooks, 2018). According to systems consolidation theory, at remote points the memory trace should depend more on cortical areas rather than subcortical regions (Hardt and Nadel, 2018). It is plausible to think the motor map expansion as the learning mode that further consolidate the motor memory in the complex cortico-striatal-thalamo-cortical loops. Further studies should demonstrate the role of striatal and thalamic lesions on motor maps following learned skilled behavior and in non-dexterous motor controls. In non-trained animals, motor maps are not affected by either medial or lateral striatal lesions, suggesting that motor impairments after such lesions are not simply related to motor map alterations (Karl et al., 2008). It is still to be answered if this is the case for skilled trained animals, and also for post-stroke reemergence and reorganization of motor maps. In a recent study, it was shown that striatal lesions are important for spontaneous recovery of non-skilled tasks (i.e., cylinder task) but not for dexterous reaching behavior (i.e., staircase task) (Karthikeyan et al., 2018). This is in accordance with the emerging consensus on the concept of cortical control over skilled motor behavior (Papale and Hooks, 2018).

Does motor map size really matter for consolidated motor skills? We suggest that future studies should focus more on the complexity and quality of the motor output, not strictly the size, given the above-mentioned dynamic nature of motor map size on short time scales (Molina-Luna et al., 2008; Reed et al., 2011). One suggested possibility is that M1 outputs captured by motor mapping may be necessary for driving plasticity in downstream structures or for initiating consolidation processes (Papale and Hooks, 2018). This consolidation would take place somewhere along the cortico-striatal-thalamo-cortical loops. The reflection of such consolidation should not always relate to increased size of motor representations, but to its efficiency in driving functional combinations of movements. For example, motor maps can be categorized in complex multiplanar movements such as abduction and adduction (Harrison et al., 2012; Bonazzi et al., 2013). Additionally, post-stroke emergence of abnormal movements or synergies in rats suggests that relearning may involve motor map reorganization to generate functional control of such complex movements (Balbinot et al., 2018). In our opinion this may not always be reflected by a greater size of motor representation, but to its content, such as the combination of different cortical modules for efficient post-stroke compensation.

\section{DIASCHISIS AS A CONSOLIDATION-RECONSOLIDATION PROCESS}

von Monakow's theory of diaschisis describes neurophysiological changes distant to a focal brain lesion (von Monakow, 1914; Carrera and Tononi, 2014). Accordingly, this concept posits that functional changes in brain structures remote from the site of a focal brain damage can underlie functional recovery following stroke (Witte, 1998; Seitz et al., 1999). Diaschisis can be subdivided into two types: ( 1 - focal diaschisis) reduction of energy metabolism at rest or during activation in anatomically intact brain regions distant from the lesion; $(2-$ non-focal diaschisis) change in coupling between two regions of a defined network or connectome involving areas distant from the lesion (Carrera and Tononi, 2014). For example, ipsilesional thalamic diaschisis is characterized by thalamic hypoperfusion in the acute phase of stroke patients (Reidler et al., 2018). Ginsberg et al. (1989) showed evidence of functional thalamic diaschisis following small thrombotic infarct in rats-in the form of impaired thalamo-cortical activation, in other words, thalamic activation was normal at rest but failed to exhibit the expected increment in response when stimulated. Similarly, Carmichael et al. (2004) described acute hypometabolism in a broad region of cortex adjacent to the stroke, striatum and thalamus - not related to cerebral blood flow reduction or reperfusion injury. At chronic stages, the ipsilesional cortical diaschisis still encompassed an area $\approx 13$ times larger than the infarct (Carmichael et al., 2004). The authors suggest that the overlap of axonal sprouting and cortical hypometabolism are likely related to a process of neuronal reorganization and reconnection following stroke (Carmichael et al., 2004). Interestingly, functional diaschisis may involve reduced activation of some areas, but increased responsiveness of others (Carrera and Tononi, 2014). Suggesting that diaschisis is more than simple loss of function, but changed function of areas distant to the lesion.

Is diaschisis a cause or consequence of this process of neuronal reorganization and reconnection? It is interestingly how diaschisis occurs early following stroke and that rehabilitation optimally affect behavioral outcome also at this early time point. It is likely that diaschisis is a gross, brain wide process of reorganization, much less subtle than a reconsolidation process, for example. Albeit different, this neuronal reorganization and reconnection must involve the classical and well described mechanisms of consolidation and reconsolidation of motor memories. Motor map/engram integrity requires continuous expression of specific proteins, such as local injections of protein synthesis inhibitors (e.g., ANI, cycloheximide) results in loss of movement representations (Kleim et al., 2003). A possibility is that motor maps are constitutively plastic, its existence relies upon constant presence of specific neural signals (Monfils et al., 2005). Once stroke disrupts these specific neural signals to distant regions, the related regions change functionality. Thus, it is reasonable to think that diaschisis would not be a cause, but a consequence of neuronal reorganization and reconnection processes.

Given the aforementioned positive role of rehabilitation during this early period of changed function, it is possible that learning mechanisms can tailor this neuronal reorganization and reconnection process. In the light of the motor learning school, this process of neuronal reorganization and reconnection could be described as a process of 'rebuilding' the motor engram/map to regain function - such as during consolidation/reconsolidation of motor memories. 


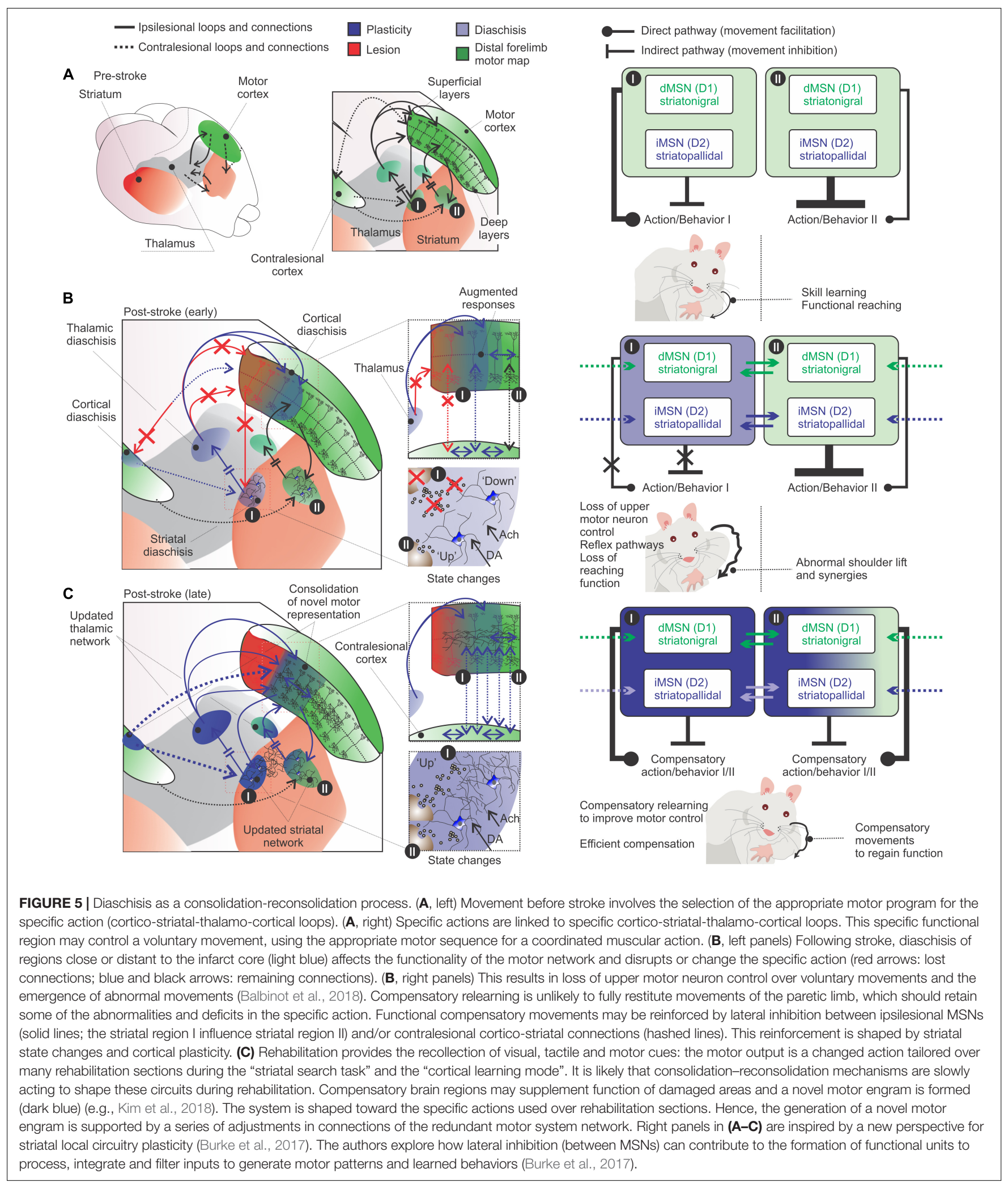

Indeed, previously consolidated motor memories can undergo a labile state upon reactivation. The reactivated motor memory can be modified through reconsolidation
(Walker et al., 2003; Censor et al., 2010; de Beukelaar et al., 2014, 2016). If this is the case, rehabilitation would promote such recollection of visual, tactile and spatial 
cues to provide cortical and striatal systems with relevant information to rebuild the motor engram. Relearning should involve the reconsolidation of previous motor loops that were not completely destroyed by the lesion, they are updated. For example, in remote regions that undewent diaschisis following stroke. Additionally, consolidation of novel compensatory motor engrams - novel connections to compensate for the loss of tissue and motor network function (Figure 5).

Abundant evidence of learning-like plasticity at both, close and remote regions, have been reported following stroke. For example, axonal sprouting within local projections, intracortical projections, long distance interhemispheric projections and cortico-striatal projections (Wilson, 1987; Lévesque et al., 1996; Carmichael and Chesselet, 2002; Carmichael, 2003). These cortical plastic changes are supported by the induction of growth-promoting genes (Brown and Murphy, 2007), also induced by motor learning (Cheung et al., 2013; Hertler et al., 2016). Striatal gene expression also occurs after a new complex motor task is memorized and most of the upregulated genes are associated with synaptic plasticity (D’Amours et al., 2011). Overall, the permissive environment following stroke leads to cortical rewiring (Winship and Murphy, 2008) and this phenomenon may be experience- and timedependent. This suggests that plasticity, experience- and timedependence are common attributes of both stroke recovery and consolidation-reconsolidation processes. In addition, recent evidence shows that the classic molecule CREB, involved in many learning processes, controls cortical circuit plasticity and functional recovery following stroke (Caracciolo et al., 2018). These learning-like plastic changes may relate to consolidation-reconsolidation of 'novel' or 'updated' motor engrams/maps.

Rehabilitative experience may slowly shape these new connections in a constant process of consolidationreconsolidation of motor memories. Given the complex and continuous nature of the rehabilitation stimulus, these processes would evolve and change continuously. In other words, the consolidation-reconsolidation process of motor memories would change throughout multiple trials. This is more challenging to understand compared to declarative or fear memories that often are treated as a single trial event. Despite these differences, the understanding that recovery/relearning of movements may share the same classic mechanisms involved in learning and memory opens a new venue of timed and focused interventions during rehabilitation. For example, the timed use of learning enhancing drugs before, during or after rehabilitation sections. Or, use of protein synthesis inhibitors upon reactivation of maladaptive motor programs, such as dysfunctional compensation or learned bad-use.

\section{CONCLUSION}

Optimization of stroke recovery focused on learning mechanisms should follow the same logic of previous learning and memory studies. The fact that the motor skill redevelops slower, across multiple trials, presents a challenge for preclinical studies on the mechanisms of poststroke compensatory relearning (Schubring-Giese et al., 2007). Recovery following stroke is related to rewiring at many corticospinal tract regions and requires upstream cortical commands (Lindau et al., 2014; Wahl and Schwab, 2014; Wahl et al., 2014). The deep cortico-striatal network plays a pivotal role on the selection of actions (Arber and Costa, 2018) and a putative role on selection of compensatory actions following stroke. Cortico-thalamocortical loops are relayed by the striatal network that is drastically changed following stroke. The denervated striatum receives increased crossed cortico-striatal connections and undergo plastic changes. In search for functional action, the striatal network participates on the reorganization of the motor system and uses spared and compensatory motor networks. As the system reorganizes, rehabilitation should induce functional compensatory movements (large lesions) or full restitution of functional movements (smaller lesions) (Murphy and Corbett, 2009; Jones, 2017). Rehabilitation therapies should focus on how to improve relearning.

Several cortical and striatal cellular mechanisms that influence motor learning may also influence post-stroke compensatory relearning, such as: $\mathrm{mGlu}_{5} \mathrm{Rs}$ agonists (Homayoun et al., 2004), 5-HT reuptake inhibition (McCann et al., 2014), cholinergic system manipulation to induce plasticity (Ramanathan et al., 2009; Conner et al., 2010) and improve post-stroke rehabilitation/relearning (Wang et al., 2016), dopaminergic manipulation (Ogura et al., 2005; Akita et al., 2006; Brown et al., 2009, 2011; Hosp et al., 2011; Kawashima et al., 2012; Hosp and Luft, 2013), selective manipulation of dorsolateral striatum matrix compartment (Lopez-Huerta et al., 2016), NMDARs manipulation in the dorsolateral striatum (Dang et al., 2006; Beutler et al., 2011; LemayClermont et al., 2011) and modulation of FS interneurons in the dorsolateral striatum (Kao et al., 2015; Xu et al., 2016).

If the motor recovery process is directly shaped by corticalstriatal-thalamic interactions, whatever changes downstream must be secondary to this relearning process. For example, the importance of spinal cord (Lindau et al., 2014; Wahl et al., 2014) and red nucleus (Mosberger et al., 2018) plasticity for stroke recovery. Thus, optimizing relearning focusing on cortical-striatal-thalamic interactions is likely acting directly on the mechanism that induce learning-related plasticity both, in site and downstream to the lesion. Despite the importance of the striatum to learning, evidence of striatal participation on stroke recovery is lacking. In addition, the majority of basic stroke research studies does not fully address the role of striatal lesions and mechanisms (Edwardson et al., 2017).

In vivo recordings have changed the way we think about motor learning (Costa et al., 2004), motor recovery (Ramanathan et al., 2018) and sensorimotor representation plasticity following stroke (Harrison et al., 2013). The most pressing 
question facing researchers have evolved from where recovery occurs, to how it occurs. We suggest that unveiling how the recovery/relearning process occurs is like to take a walk on a well know path of motor learning. This path should remind us that neural activity and synaptic plasticity are constantly interacting, both at individual synapses and within neural circuits. Our challenge is to understand how they operate in a behaving brain to support post-stroke compensatory relearning.

\section{AUTHOR CONTRIBUTIONS}

GB wrote the manuscript and drawn the figures. CS reviewed the manuscript.

\section{REFERENCES}

Akita, H., Ogata, M., Jitsuki, S., Ogura, T., Oh-Nishi, A., Hoka, S., et al. (2006). Nigral injection of antisense oligonucleotides to synaptotagmin I using HVJliposome vectors causes disruption of dopamine release in the striatum and impaired skill learning. Brain Res. 1095, 178-189. doi: 10.1016/j.brainres.2006. 04.039

Alia, C., Spalletti, C., Lai, S., Panarese, A., Micera, S., and Caleo, M. (2016). Reducing GABAA-mediated inhibition improves forelimb motor function after focal cortical stroke in mice. Sci. Rep. 6:37823. doi: 10.1038/srep 37823

Amitai, Y. (2001). Thalamocortical synaptic connections: efficacy, modulation, inhibition and plasticity. Rev. Neurosci. 12, 159-173. doi: 10.1515/REVNEURO. 2001.12.2.159

Amitai, Y., and Connors, B. W. (1995). "Intrinsic physiology and morphology of single neurons in neocortex," in The Barrel Cortex of Rodents, eds E. G. Jones and I. Diamond (New York, NY: Plenum Press), 299-331.

Anderson, C. T., Sheets, P. L., Kir-itani, T., and Shepherd, G. M. (2010). Sublayerspecific microcircuits of corticospinal and corticostriatal neurons in motor cortex. Nat. Neurosci. 13, 739-744. doi: 10.1038/nn.2538

Arber, S., and Costa, R. M. (2018). Connecting neuronal circuits for movement. Science 360, 1403-1404. doi: 10.1126/science.aat5994

Ariano, M. A., Fisher, R. S., Smyk-Randall, E., Sibley, D. R., and Levine, M. S. (1993). D2 dopamine receptor distribution in the rodent CNS using anti-peptide antisera. Brain Res. 609, 71-80. doi: 10.1016/0006-8993(93) 90857-J

Awenowicz, P. W., and Porter, L. L. (2002). Local application of dopamine inhibits pyramidal tract neuron activity in the rodent motor cortex. J. Neurophysiol. 88, 3439-3451. doi: 10.1152/jn.00078.2002

Balbinot, G., Schuch, C. P., Jeffers, M. S., McDonald, M. W., Livingston-Thomas, J. M., and Corbett, D. (2018). Post-stroke kinematic analysis in rats reveals similar reaching abnormalities as humans. Sci. Rep. 8:8738. doi: 10.1038/ s41598-018-27101-0

Bamford, N. S., Wightman, R. M., and Sulzer, D. (2018). Dopamine's effects on corticostriatal synapses during reward-based behaviors. Neuron 97, 494-510. doi: 10.1016/j.neuron.2018.01.006

Beutler, L. R., Eldred, K. C., Quintana, A., Keene, C. D., Rose, S. E., Postupna, N., et al. (2011). Severely impaired learning and altered neuronal morphology in mice lacking NMDA receptors in medium spiny neurons. PLoS One 6:11. doi: 10.1371/journal.pone.0028168

Biane, J. S., Takashima, Y., Scanziani, M., Conner, J. M., and Tuszynski, M. H. (2016). Thalamocortical projections onto behaviorally relevant neurons exhibit plasticity during adult motor learning. Neuron 89, 1173-1179. doi: 10.1016/j. neuron.2016.02.001

Biernaskie, J., Chernenko, G., and Corbett, D. (2004). Efficacy of rehabilitative experience declines with time after focal ischemic brain injury. J. Neurosci. 24, 1245-1254. doi: 10.1523/JNEUROSCI.3834-03.2004

Biernaskie, J., and Corbett, D. (2001). Enriched rehabilitative training promotes improved forelimb motor function and enhanced dendritic growth after focal

\section{FUNDING}

This work was supported by a grant from the Canadian Government - Emerging Leaders in the Americas Program (ELAP; CIC \#509/2016) and by Coordenação de Aperfeiçoamento de Pessoal de Nível Superior (CAPES/Brazil).

\section{ACKNOWLEDGMENTS}

We thank Ph.D. Numa Dancause for insightful comments and directions in a previous version of this manuscript. We also thank Ph.D. Martín Cammarota and Ph.D. Adriano B.L. Tort for supervision and support, respectively.

ischemic injury. J. Neurosci. 21, 5272-5280. doi: 10.1523/JNEUROSCI.21-1405272.2001

Bonazzi, L., Viaro, R., Lodi, E., Canto, R., Bonifazzi, C., and Franchi, G. (2013). Complex movement topography and extrinsic space representation in the rat forelimb motor cortex as defined by long-duration intracortical microstimulation. J. Neurosci. 33, 2097-2107. doi: 10.1523/JNEUROSCI.345412.2013

Brimblecombe, K. R., and Cragg, S. J. (2015). Substance P weights striatal dopamine transmission differently within the striosome-matrix axis. J. Neurosci. 35, 90179023. doi: 10.1523/JNEUROSCI.0870-15.2015

Brown, A. R., Antle, M. C., Hu, B., and Teskey, G. C. (2011). High frequency stimulation of the subthalamic nucleus acutely rescues motor deficits and neocortical movement representations following 6-hydroxydopamine administration in rats. Exp. Neurol. 231, 82-90. doi: 10.1016/j.expneurol.2011. 05.017

Brown, C. E., Aminoltejari, K., Erb, H., Winship, I. R., and Murphy, T. H. (2009). In vivo voltage-sensitive dye imaging in adult mice reveals that somatosensory maps lost to stroke are replaced over weeks by new structural and functional circuits with prolonged modes of activation within both the peri-infarct zone and distant sites. J. Neurosci. 29, 1719-1734. doi: 10.1523/JNEUROSCI.424908.2009

Brown, C. E., and Murphy, T. H. (2007). Livin' on the edge: imaging dendritic spine turnover in the peri-infarct zone during ischemic stroke and recovery. Neuroscientist 14, 139-146. doi: 10.1177/1073858407309854

Burke, D. A., Rotstein, H. G., and Alvarez, V. A. (2017). Striatal local circuitry: a new framework for lateral inhibition. Neuron 96, 267-284. doi: 10.1016/j. neuron.2017.09.019

Calabresi, P., Centonze, D., Gubellini, P., Marfia, G. A., Pisani, A., Sancesario, G., et al. (2000). Synaptic transmission in the striatum: from plasticity to neurodegeneration. Prog. Neurobiol. 61, 231-265. doi: 10.1016/S0301-0082(99) 00030- 1

Calabresi, P., Picconi, B., Tozzi, A., and Di Filippo, M. (2007). Dopamine-mediated regulation of corticostriatal synaptic plasticity. Trends Neurosci. 30, 211-219. doi: 10.1016/j.tins.2007.03.001

Calabresi, P., Picconi, B., Tozzi, A., Ghiglieri, V., and Di Filippo, M. (2014). Direct and indirect pathways of basal ganglia: a critical reappraisal. Nat. Neurosci. 17, 1022-1030. doi: 10.1038/nn.3743

Calabresi, P., Pisani, A., Mercuri, N. B., and Bernardi, G. (1992). Long-term potentiation in the striatum is unmasked by removing the voltage-dependent magnesium block of NMDA receptor channels. Eur. J. Neurosci. 4, 929-935. doi: 10.1111/j.1460-9568.1992.tb00119.x

Calabresi, P., Pisani, A., Mercuri, N. B., and Bernardi, G. (1994). Post-receptor mechanisms underlying striatal long-term depression. J. Neurosci. 14, 48714881. doi: 10.1523/JNEUROSCI.14-08-04871.1994

Calabresi, P., Pisani, A., Mercuri, N. B., and Bernardi, G. (1996). The corticostriatal projection: from synaptic plasticity to dysfunctions of the basal ganglia. Trends Neurosci. 19, 19-24. doi: 10.1016/0166-2236(96)81862-5

Calabresi, P., Saiardi, A., Pisani, A., Baik, J. H., Centonze, D., Mercuri, N. B., et al. (1997). Abnormal synaptic plasticity in the striatum of mice lacking dopamine 
D2 receptors. J. Neurosci. 17, 4536-4544. doi: 10.1523/JNEUROSCI.17-1204536.1997

Caracciolo, L., Marosi, M., Mazzitelli, J., Latifi, S., Sano, Y., Galvan, L., et al. (2018). CREB controls cortical circuit plasticity and functional recovery after stroke. Nat. Commun. 9:2250. doi: 10.1038/s41467-018-04445-9

Carmichael, S. T. (2003). Plasticity of cortical projections after stroke. Neuroscientist 9, 64-75. doi: 10.1177/1073858402239592

Carmichael, S. T., Archibeque, I., Luke, L., Nolan, T., Momiy, J., and Li, S. (2005). Growth-associated gene expression after stroke: evidence for a growthpromoting region in peri-infarct cortex. Exp. Neurol. 193, 291-311. doi: 10. 1016/j.expneurol.2005.01.004

Carmichael, S. T., and Chesselet, M. F. (2002). Synchronous neuronal activity is a signal for axonal sprouting after cortical lesions in the adult. J. Neurosci. 22, 6062-6070. doi: 10.1523/JNEUROSCI.22-14-06062.2002

Carmichael, S. T., Tatsukawa, K., Katsman, D., Tsuyuguchi, N., and Kornblum, H. I. (2004). Evolution of diaschisis in a focal stroke model. Stroke 35, 758-763. doi: 10.1161/01.STR.0000117235.11156.55

Carregosa, A. A., Aguiar Dos Santos, L. R., Masruha, M. R., Coêlho, M. L. D. S., Machado, T. C., Souza, D. C. B., et al. (2018). Virtual rehabilitation through Nintendo Wii in poststroke patients: follow-up. J. Stroke Cerebrovasc. Dis. 27, 494-498. doi: 10.1016/j.jstrokecerebrovasdis.2017.09.029

Carrera, E., and Tononi, G. (2014). Diaschisis: past, present, future. Brain 137(Pt 9), 2408-2422. doi: 10.1093/brain/awu101

Castro-Alamancos, M. A., and Borrell, J. (1995). Contribution of NMDA and nonNMDA glutamate receptors to synchronized excitation and cortical output in the primary motor cortex of the rat. Brain Res. Bull. 37, 539-543. doi: 10.1016/0361-9230(95)00059-N

Castro-Alamancos, M. A., and Connors, B. W. (1996a). Cellular mechanisms of the augmenting response: short-term plasticity in a thalamocortical pathway. J. Neurosci. 16, 7742-7756.

Castro-Alamancos, M. A., and Connors, B. W. (1996b). Short-term plasticity of a thalamocortical pathway dynamically modulated by behavioral state. Science $272,274-277$

Castro-Alamancos, M. A., and Connors, B. W. (1996c). Spatiotemporal properties of short-term plasticity sensorimotor thalamocortical pathways of the rat. J. Neurosci. 16, 2767-2779.

Castro-Alamancos, M. A., and Connors, B. W. (1997). Thalamocortical synapses. Prog. Neurobiol. 6, 581-606. doi: 10.1016/S0301-0082(97)00002-6

Cavaccini, A., Gritti, M., Giorgi, A., Locarno, A., Heck, N., Migliarini, S., et al. (2018). Serotonergic signaling controls input-specific synaptic plasticity at striatal circuits. Neuron 98, 801.e7-816.e7. doi: 10.1016/j.neuron.2018. 04.008

Celada, P., Puig, M. V., and Artigas, F. (2013). Serotonin modulation of cortical neurons and networks. Front. Integr. Neurosci. 7:25. doi: 10.3389/fnint.2013. 00025

Censor, N., Dimyan, M. A., and Cohen, L. G. (2010). Modification of existing human motor memories is enabled by primary cortical processing during memory reactivation. Curr. Biol. 20, 1545-1549. doi: 10.1016/j.cub.2010. 07.047

Cerovic, M., D'Isa, R., Tonini, R., and Brambilla, R. (2013). Molecular and cellular mechanisms of dopamine-mediated behavioral plasticity in the striatum. Neurobiol. Learn. Mem. 105, 63-80. doi: 10.1016/j.nlm.2013.06.013

Chapman, C. A., Trepel, C., Ivanco, T. L., Froc, D. J., Wilson, K., and Racine, R. J. (1998). Changes in field potentials and membrane currents in rat sensorimotor cortex following repeated tetanization of the corpus callosum in vivo. Cereb. Cortex 8, 730-742. doi: 10.1093/cercor/8.8.730

Charpier, S., and Deniau, J. M. (1997). In vivo activity-dependent plasticity at cortico-striatal connections: evidence for physiological long-term potentiation. Proc. Natl. Acad. Sci. U.S.A. 94, 7036-7040. doi: 10.1073/pnas.94.13.7036

Cheng, H. W., Tong, J., and McNeill, T. H. (1998). Ultrastructural evidence for cortical axon sprouting in the deafferented striatum of adult rat. Neurosci. Lett. $241,1-4$.

Cheung, V. C., Deboer, C., Hanson, E., Tunesi, M., D’Onofrio, M., Arisi, I., et al. (2013). Gene expression changes in the motor cortex mediating motor skill learning. PLoS One 8:e61496. doi: 10.1371/journal.pone.0061496

Clarke, J., Langdon, K. D., and Corbett, D. (2014). Early poststroke experience differentially alters periinfarct layer II and III cortex. J. Cereb. Blood Flow Metab. 34, 630-637. doi: 10.1038/jcbfm.2013.237
Cohen, J. D., and Castro-Alamancos, M. A. (2005). Skilled motor learning does not enhance long-term depression in the motor cortex in vivo. J. Neurophysiol. 93, 1486-1497. doi: 10.1152/jn.00958.2004

Conn, J. P., and Pin, J. P. (1997). Pharmacology and functions of metabotropic glutamate receptors. Ann. Rev. Pharmacol. Toxicol. 37, 205-237. doi: 10.1146/ annurev.pharmtox.37.1.205

Conner, J. M., Chiba, A. A., and Tuszynski, M. H. (2005). The basal forebrain cholinergic system is essential for cortical plasticity and functional recovery following brain injury. Neuron 46, 173-179. doi: 10.1016/j.neuron.2005.03.003

Conner, J. M., Culberson, A., Packowski, C., Chiba, A. A., and Tuszynski, M. H. (2003). Lesions of the basal forebrain cholinergic system impair task acquisition and abolish cortical plasticity associated with motor skill learning. Neuron 38, 819-829. doi: 10.1016/S0896-6273(03)00288-5

Conner, J. M., Kulczycki, M., and Tuszynski, M. H. (2010). Unique contributions of distinct cholinergic projections to motor cortical plasticity and learning. Cereb. Cortex 20, 2739-2748. doi: 10.1093/cercor/bhq022

Cortés, R., and Palacios, J. M. (1986). Muscarinic cholinergic receptor subtypes in the rat brain. I. Quantitative autoradiographic studies. Brain Res. 362, 227-238. doi: 10.1016/0006-8993(86)90448-8

Costa, R. M., Cohen, D., and Nicolelis, M. A. (2004). Differential corticostriatal plasticity during fast and slow motor skill learning in mice. Curr. Biol. 14, 1124-1134. doi: 10.1016/j.cub.2004.06.053

Cowan, R. L., and Wilson, C. J. (1994). Spontaneous firing patterns and axonal projections of single corticostriatal neurons in the rat medial agranular cortex. J. Neurophysiol. 71, 17-32. doi: 10.1152/jn.1994.71.1.17

Cui, G., Jun, S. B., Jin, X., Pham, M. D., Vogel, S. S., Lovinger, D. M., et al. (2013). Concurrent activation of striatal direct and indirect pathways during action initiation. Nature 494, 238-242. doi: 10.1038/nature11846

Cui, Y., Paillé, V., Xu, H., Genet, S., Delord, B., Fino, E., et al. (2015). Endocannabinoids mediate bidirectional striatal spike-timing-dependent plasticity. J. Physiol. 593, 2833-2849. doi: 10.1113/JP270324

Cui, Y., Prokin, I., Xu, H., Delord, B., Genet, S., Venance, L., et al. (2016). Endocannabinoid dynamics gate spike- timing dependent depression and potentiation. eLife 5:e13185. doi: 10.7554/eLife.13185

D’Amours, G., Bureau, G., Boily, M. J., and Cyr, M. (2011). Differential gene expression profiling in the mouse brain during motor skill learning: focus on the striatum structure. Behav. Brain Res. 221, 108-117. doi: 10.1016/j.bbr.2011. 02.030

Dancause, N. (2006). Vicarious function of remote cortex following stroke: recent evidence from human and animal studies. Neuroscientist 12, 489-499. doi: $10.1177 / 1073858406292782$

Dancause, N., Touvykine, B., and Mansoori, B. (2015). Inhibition of the contralesional hemisphere after stroke: reviewing a few of the building blocks with a focus on animal models. Prog. Brain Res. 218, 361-387. doi: 10.1016/bs. pbr.2015.01.002

Dang, M. T., Yokoi, F., Yin, H. H., Lovinger, D. M., Wang, Y., and Li, Y. (2006). Disrupted motor learning and long-term synaptic plasticity in mice lacking NMDAR1 in the striatum. Proc. Natl. Acad. Sci. U.S.A. 103, 15254-15259. doi: $10.1073 /$ pnas. 0601758103

Davis, M. I., Crittenden, J. R., Feng, A. Y., Kupferschmidt, D. A., Naydenov, A., Stella, N., et al. (2018). The cannabinoid-1 receptor is abundantly expressed in striatal striosomes and striosome-dendron bouquets of the substantia nigra. PLoS One 13:e0191436. doi: 10.1371/journal.pone.0191436

de Beukelaar, T. T., Woolley, D. G., Alaerts, K., Swinnen, S. P., and Wenderoth, N. (2016). Reconsolidation of motor memories is a time-dependent process. Front. Hum. Neurosci. 10:408. doi: 10.3389/fnhum.2016.00408

de Beukelaar, T. T., Woolley, D. G., and Wenderoth, N. (2014). Gone for 60 seconds: reactivation length determines motor memory degradation during reconsolidation. Cortex 59, 138-145. doi: 10.1016/j.cortex.2014.07.008

Ding, J., Peterson, J. D., and Surmeier, D. J. (2008). Corticostriatal and thalamostriatal synapses have distinctive properties. J. Neurosci. 28, 6483-6492. doi: 10.1523/JNEUROSCI.0435-08.2008

Ding, J. B., Guzman, J. N., Peterson, J. D., Goldberg, J. A., and Surmeier, D. J. (2010). Thalamic gating of corticostriatal signaling by cholinergic interneurons. Neuron 67, 294-307. doi: 10.1016/j.neuron.2010.06.017

Donoghue, J. P., and Kitai, S. T. (1981). A collateral pathway to the neostriatum from corticofugal neurons of the rat sensorimotor cortex: an intracellular study. J. Comp. Neurol. 201, 1-13. doi: 10.1002/cne.902010102 
Edwardson, M. A., Wang, X., Liu, B., Ding, L., Lane, C. J., Park, C., et al. (2017). Stroke lesions in a large upper limb rehabilitation trial cohort rarely match lesions in common preclinical models. Neurorehabil. Neural Repair 31, 509-520. doi: 10.1177/1545968316688799

Ellender, T. J., Harwood, J., Kosillo, P., Capogna, M., and Bolam, J. P. (2013). Heterogeneous properties of central lateral and parafascicular thalamic synapses in the striatum. J. Physiol. 591, 257-272. doi: 10.1113/jphysiol.2012. 245233

Feldman, M. L. (1984). "Morphology of the neocortical pyramidal neuron," in Cellular Components of the Cerebral Cortex, eds A. Peters and E. G. Jones (New York, NY: Plenum Press), 123-200.

Ferraguti, F., and Shigemoto, R. (2006). Metabotropic glutamate receptors. Cell Tissue Res. 326, 483-504. doi: 10.1007/s00441-006-0266-5

Fisone, G., Hakansson, K., Borgkvist, A., and Santini, E. (2007). Signaling in the basal ganglia: postsynaptic and presynaptic mechanisms. Physiol. Behav. 92, 8-14. doi: 10.1016/j.physbeh.2007.05.028

Florio, T. M., Scarnati, E., Rosa, I., Di Censo, D., Ranieri, B., Cimini, A., et al. (2018). The basal ganglia: more than just a switching device. CNS Neurosci. Ther. 24, 677-684. doi: 10.1111/cns.12987

Frey, K. A., and Howland, M. M. (1992). Quantitative autoradiography of muscarinic cholinergic receptor binding in the rat brain: distinction of receptor subtypes in antagonist competition assays. J. Pharmacol. Exp. Ther. 263, 13911400.

Fuentes, M. A., Borrego, A., Latorre, J., Colomer, C., Alcañiz, M., SánchezLedesma, M. J., et al. (2018). Combined transcranial direct current stimulation and virtual reality-based paradigm for upper limb rehabilitation in individuals with restricted movements. A feasibility study with a chronic stroke survivor with severe hemiparesis. J. Med. Syst. 42:87. doi: 10.1007/s10916-0180949-y

Galiñanes, G. L., Bonardi, C., and Huber, D. (2018). Directional reaching for water as a cortex-dependent behavioral framework for mice. Cell Rep. 22, 2601-2614. doi: 10.1016/j.celrep.2018.02.042

Gaspar, P., Bloch, B., and Le Moine, C. (1995). D1 and D2 receptor gene expression in the rat frontal cortex: cellular localization in different classes of efferent neurons. Eur. J. Neurosci. 7, 1050-1063. doi: 10.1111/j.1460-9568.1995. tb01092.x

Gerfen, C. R. (1989). The neostriatal mosaic: striatal patch-matrix organization is related to cortical lamination. Science 246, 385-388. doi: 10.1126/science. 2799392

Gerfen, C. R. (1992). The neostriatal mosaic: multiple levels of compartmental organization in the basal ganglia. Annu. Rev. Neurosci. 15, 285-320. doi: 10. 1146/annurev.ne.15.030192.001441

Ginsberg, M. D., Castella, Y., Dietrich, W. D., Watson, B. D., and Busto, R. (1989). Acute thrombotic infarction suppresses metabolic activation of ipsilateral somatosensory cortex: evidence for functional diaschisis. J. Cereb. Blood Flow Metab. 9, 329-341. doi: 10.1038/jcbfm.1989.51

Gonzalez, C. L., and Kolb, B. (2003). A comparison of different models of stroke on behaviour and brain morphology. Eur. J. Neurosci. 18, 1950-1962. doi: $10.1046 / j .1460-9568.2003 .02928 . x$

Graybiel, A. M. (1995). Building action repertoires: memory and learning functions of the basal ganglia. Curr. Opin. Neurobiol. 5, 733-741. doi: 10.1016/09594388(95) $80100-6$

Greenough, W. T., Larson, J. R., and Withers, G. S. (1985). Effects of unilateral and bilateral training in a reaching task on dendritic branching of neurons in the rat motor-sensory forelimb cortex. Behav. Neural Biol. 44, 301-314. doi: 10.1016/S0163-1047(85)90310-3

Greig, L. F. C., Woodworth, M. B., Galazo, M. J., Padmanabhan, H., and Macklis, J. D. (2013). Molecular logic of neocortical projection neuron specification, development and diversity. Nat. Rev. Neurosci. 14, 755-769. doi: 10.1038/ nrn3586

Grimm, F., Naros, G., and Gharabaghi, A. (2016). Closed-loop task difficulty adaptation during virtual reality reach-to-grasp training assisted with an exoskeleton for stroke rehabilitation. Front. Neurosci. 10:518. doi: 10.3389/ fnins. 2016.00518

Gulledge, A. T., and Jaffe, D. B. (2001). Multiple effects of dopamine on layer V pyramidal cell excitability in rat prefrontal cortex. J. Neurophysiol. 86, 586-595. doi: $10.1152 /$ jn.2001.86.2.586
Guo, J. Z., Graves, A. R., Guo, W. W., Zheng, J., Lee, A., Rodríguez-Gonzá, J., et al. (2015). Cortex commands the performance of skilled movement. eLife 4:e10774. doi: $10.7554 /$ eLife. 10774

Guy, J., and Staiger, J. F. (2017). The functioning of a cortex without layers. Front. Neuroanat. 11:54. doi: 10.3389/fnana.2017.00054

Haber, S. N., and Calzavara, R. (2009). The cortico-basal ganglia integrative network: the role of the thalamus. Brain Res. Bull. 78, 69-74. doi: 10.1016/j. brainresbull.2008.09.013

Hagemann, G., Redecker, C., Neumann-Haefelin, T., Freund, H. J., and Witte, O. W. (1998). Increased long-term potentiation in the surround of experimentally induced focal cortical infarction. Ann. Neurol. 44, 255-258. doi: 10.1002/ana.410440217

Hardt, O., and Nadel, L. (2018). Systems consolidation revisited, but not revised: the promise and limits of optogenetics in the study of memory. Neurosci. Lett. 680, 54-59. doi: 10.1016/j.neulet.2017.11.062

Harrison, T. C., Ayling, O. G. S., and Murphy, T. H. (2012). Distinct cortical circuit mechanisms for complex forelimb movement and motor map topography. Neuron 74, 397-409. doi: 10.1016/j.neuron.2012.02.028

Harrison, T. C., Silasi, G., Boyd, J. D., and Murphy, T. H. (2013). Displacement of sensory maps and disorganization of motor cortex after targeted stroke in mice. Stroke 44, 2300-2306. doi: 10.1161/STROKEAHA.113.001272

Hatem, S. M., Saussez, G., della Faille, M., Prist, V., Zhang, X., Dispa, D., et al. (2016). Rehabilitation of motor function after stroke: a multiple systematic review focused on techniques to stimulate upper extremity recovery. Front. Hum. Neurosci. 10:442. doi: 10.3389/fnhum.2016.0044

Heilbronner, S. R., Rodriguez-Romaguera, J., Quirk, G. J., Groenewegen, H. J., and Haber, S. N. (2016). Circuit based cortico-striatal homologies between rat and primate. Biol. Psychiatry 80, 509-521. doi: 10.1016/j.biopsych.2016. 05.012

Hertler, B., Buitrago, M. M., Luft, A. R., and Hosp, J. A. (2016). Temporal course of gene expression during motor memory formation in primary motor cortex of rats. Neurobiol. Learn. Mem. 136, 105-115. doi: 10.1016/j.nlm.2016.09.018

Hess, G., Aizenman, C. D., and Donoghue, J. P. (1996). Conditions for the induction of long-term potentiation in layer II/III horizontal connections of the rat motor cortex. J. Neurophysiol. 75, 1765-1778. doi: 10.1152/jn.1996.75.5.1765

Hess, G., and Donoghue, J. P. (1994). Long-term potentiation of horizontal connections provides a mechanism to reorganize cortical motor maps. J. Neurophysiol. 71, 2543-2547. doi: 10.1152/jn.1994.71.6.2543

Hjornevik, T. (2007). Three-dimensional atlas system for mouse and rat brain imaging data. Front. Neuroinform. 1:4. doi: 10.3389/neuro.11.004.2007

Homayoun, H., Stefani, M. R., Adams, B. W., Tamagan, G. D., and Moghaddam, B. (2004). Functional interaction between NMDA and mGlu5 receptors: effects on working memory, instrumental learning, motor behaviors, and dopamine release. Neuropsychopharmacology 29, 1259-1269. doi: 10.1038/sj.npp.1300417

Hosp, J., and Luft, A. R. (2013). Dopaminergic meso-cortical projections to M1: role in motor learning and motor cortex plasticity. Front. Neurol. 4:145. doi: 10.3389/fneur.2013.00145

Hosp, J. A., and Luft, A. R. (2011). Cortical plasticity during motor learning and recovery after ischemic stroke. Neural Plast. 2011:871296. doi: 10.1155/2011/ 871296

Hosp, J. A., Pekanovic, A., Rioult-Pedotti, M. S., and Luft, A. R. (2011). Dopaminergic projections from midbrain to primary motor cortex mediate motor skill learning. J. Neurosci. 31, 2481-2487. doi: 10.1523/JNEUROSCI. 5411-10.2011

Hunnicutt, B. J., Jongbloets, B. C., Birdsong, W. T., Gertz, K. J., Zhong, H., and Mao, T. (2016). A comprehensive excitatory input map of the striatum reveals novel functional organization. eLife 5:e19103. doi: 10.7554/eLife.19103

Jankowska, E., Padel, Y., and Tanaka, R. (1975). Projections of pyramidal tract cells to alpha motoneurons innervating hindlimb muscles in the monkey. J. Physiol. 249, 637-667. doi: 10.1113/jphysiol.1975.sp011035

Jeffers, M., Karthikeyan, S., and Corbett, D. (2018). Does stroke rehabilitation really matter? Part A: proportional stroke recovery in the rat. Neurorehabil. Neural Repair 32, 3-6. doi: 10.1177/1545968317751210

Johnston, J. G., Gerfen, C. R., Haber, S. N., and van der Kooy, D. (1990). Mechanisms of striatal pattern formation: conservation of mammalian compartmentalization. Brain Res. Dev. Brain Res. 57, 93-102. doi: 10.1016/ 0165-3806(90)90189-6 
Jones, T. A. (2017). Motor compensation and its effects on neural reorganization after stroke. Nat. Rev. Neurosci. 8, 267-280. doi: 10.1038/nrn.2017.26

Kaneko, T. (2013). Local connections of excitatory neurons in motor-associated cortical areas of the rat. Front. Neural Circuits 7:75. doi: 10.3389/fncir.2013. 00075

Kao, F. C., Su, S. H., Carlson, G. C., and Liao, W. (2015). MeCP2-mediated alterations of striatal features accompany psychomotor deficits in a mouse model of Rett syndrome. Brain Struct. Funct. 220, 419-434. doi: 10.1007/ s00429-013-0664-x

Karl, J. M., Sacrey, L. A. R., McDonald, R. J., and Whishaw, I. Q. (2008). Intact intracortical microstimulation (ICMS) representations of rostral and caudal forelimb areas in rats with quinolinic acid lesions of the medial or lateral caudate-putamen in an animal model of Huntington's disease. Brain Res. Bull. 77, 42-48. doi: 10.1016/j.brainresbull.2008.04.012

Karni, A., Meyer, G., Rey-Hipolito, C., Jezzard, P., Adams, M. M., Turner, R., et al. (1998). The acquisition of skilled motor performance: fast and slow experiencedriven changes in primary motor cortex. Proc. Natl. Acad. Sci. U.S.A. 95, 861-868. doi: 10.1073/pnas.95.3.861

Karthikeyan, S., Jeffers, M. S., Carter, A., and Corbett, D. (2018). Characterizing spontaneous motor recovery following cortical and subcortical stroke in the rat. Neurorehabil. Neural Repair doi: 10.1177/1545968318817823 [Epub ahead of print].

Kawaguchi, Y., and Shindou, T. (1998). Noradrenergic excitation and inhibition of GABAergic cell types in rat frontal cortex. J. Neurosci. 18, 6963-6976. doi: 10.1523/JNEUROSCI.18-17-06963.1998

Kawai, R., Markman, T., Poddar, R., Ko, R., Fantana, A. L., Dhawale, A. K., et al. (2015). Motor cortex is required for learning but not for executing a motor skill. Neuron 86, 800-812. doi: 10.1016/j.neuron.2015.03.024

Kawashima, S., Ueki, Y., Kato, T., Matsukawa, N., Mima, T., Hallett, M., et al. (2012). Changes in striatal dopamine release associated with human motor-skill acquisition. PLoS One 7:e31728. doi: 10.1371/journal.pone.0031728

Kemp, J. M., and Powell, T. P. (1971). The termination of fibres from the cerebral cortex and thalamus upon dendritic spines in the caudate nucleus: a study with the Golgi method. Philos. Trans. R. Soc. Lond. B Biol. Sci. 262, 429-439. doi: 10.1098/rstb.1971.0105

Kerner, J. A., Standaert, D. G., Penney, J. B., Young, A. B., and Landwehrmeyer, G. B. (1997). Expression of group one metabotropic glutamate receptor subunit mRNAs in neurochemically identified neurons in the rat neostriatum, neocortex, and hippocampus. Brain Res. Mol. Brain Res. 48, 259-269. doi: 10.1016/S0169-328X(97)00102-2

Kheirbek, M. A., Britt, J. P., Beeler, J. A., Ishikawa, Y., McGehee, D. S., and Zhuang, X. (2009). Adenylyl cyclase type 5 contributes to corticostriatal plasticity and striatum-dependent learning. J. Neurosci. 29, 12115-12124. doi: 10.1523/JNEUROSCI.3343-09.2009

Kim, S. Y., Hsu, J. E., Husbands, L. C., Kleim, J. A., and Jones, T. A. (2018). Coordinated plasticity of synapses and astrocytes underlies practice-driven functional vicariation in peri-infarct motor cortex. J. Neurosci. 38, 93-107. doi: 10.1523/JNEUROSCI.1295-17.2017

Kincaid, A. E., and Wilson, C. J. (1996). Corticostriatal innervation of the patch and matrix in the rat neostriatum. J. Comp. Neurol. 374, 578-592. doi: 10.1002/ (SICI) 1096-9861(19961028)374:4<578::AID-CNE7>3.0.CO;2-Z

Kleim, J. A., Barbay, S., and Nudo, R. J. (1998). Functional reorganization of the rat motor cortex following motor skill learning. J. Neurophysiol. 80, 3321-3325. doi: 10.1152/jn.1998.80.6.3321

Kleim, J. A., Bruneau, R., Calder, K., Pocock, D., VandenBerg, P. M., MacDonald, E., et al. (2003). Functional organization of adult motor cortex is dependent upon continued protein synthesis. Neuron 40, 167-176. doi: 10. 1016/S0896-6273(03)00592-0

Kleim, J. A., Hogg, T. M., VandenBerg, P. M., Cooper, N. R., Bruneau, R., and Remple, M. (2004). Cortical synaptogenesis and motor map reorganization occur during late, but not early, phase of motor skill learning. J. Neurosci. 24, 628-633. doi: 10.1523/JNEUROSCI.3440-03.2004

Kolb, B., Cioe, J., and Comeau W. (2008). Contrasting effects of motor and visual spatial learning tasks on dendritic arborization and spine density in rats. Neurobiol. Learn. Mem. 90, 295-300. doi: 10.1016/j.nlm.2008.04.012

Korchounov, A., and Ziemann, U. (2011). Neuromodulatory neurotransmitters influence LTP-like plasticity in human cortex: a pharmaco-TMS study. Neuropsychopharmacology 36, 1894-1902. doi: 10.1038/npp.2011.75
Krakauer, J. W. (2006). Motor learning: its relevance to stroke recovery and neurorehabilitation. Curr. Opin. Neurol. 19, 84-90. doi: 10.1097/01.wco. 0000200544.29915.cc

Krakauer, J. W., Carmichael, S. T., Corbett, D., and Wittenberg, G. F. (2012). Getting neurorehabilitation right: what can be learned from animal models? Neurorehabil. Neural Repair 26, 923-931. doi: 10.1177/1545968312440745

Krakauer, J. W., and Shadmehr, R. (2006). Consolidation of motor memory. Trends Neurosci. 29, 58-64. doi: 10.1016/j.tins.2005.10.003

Kreitzer, A. C. (2009). Physiology and pharmacology of striatal neurons. Annu. Rev. Neurosci. 32, 127-147. doi: 10.1146/annurev.neuro.051508.135422

Kreitzer, A. C., and Malenka, R. C. (2005). Dopamine modulation of statedependent endocannabinoid release and long-term depression in the striatum. J. Neurosci. 25, 10537-10545. doi: 10.1523/JNEUROSCI.2959-05.2005

Kreitzer, A. C., and Malenka, R. C. (2008). Striatal plasticity and basal ganglia circuit function. Neuron 60, 543-554. doi: 10.1016/j.neuron.2008.11.005

Kupferschmidt, D. A., Juczewski, K., Cui, G., Johnson, K. A., and Lovinger, D. M. (2017). Parallel, but dissociable, processing in discrete corticostriatal inputs encodes skill learning. Neuron 96, 476.e5-489.e5. doi: 10.1016/j.neuron.2017. 09.040

Kuramoto, E., Furuta, T., Nakamura, K. C., Unzai, T., Hioki, H., and Kaneko, T. (2009). Two types of thalamocortical projections from themotor thalamic nuclei of the rat: a single neuron-tracing study using viral vectors. Cereb. Cortex 19, 2065-2077. doi: 10.1093/cercor/bhn231

Lança, A. J., Boyd, S., Kolb, B. E., and van der Kooy, D. (1986). The development of a patchy organization of the rat striatum. Dev. Brain Res. 27, 1-10. doi: 10.1016/0165-3806(86)90226-9

Lemay-Clermont, J., Robitaille, C., Auberson, Y. P., Bureau, G., and Cyr, M. (2011). Blockade of NMDA receptors $2 \mathrm{~A}$ subunit in the dorsal striatum impairs the learning of a complex motor skill. Behav. Neurosci. 125, 714-723. doi: 10.1037/ a 0025213

Lévesque, M., Charara, A., Gagnon, S., Parent, A., and Deschênes, M. (1996). Corticostriatal projections from layer $\mathrm{V}$ cells in rat are collaterals of longrange corticofugal axons. Brain Res. 709, 311-315. doi: 10.1016/0006-8993(95) 01333-4

Leyva-Díaz, E., and López-Bendito, G. (2013). In and out from the cortex: development of major forebrain connections. Neuroscience 254, 26-44. doi: 10.1016/j.neuroscience.2013.08.070

Li, Y., Jiang, N., Powers, C., and Chopp, M. (1998). Neuronal damage and plasticity identified by microtubule-associated protein 2 , growth-associated protein 43 , and cyclin D1 immunoreactivity after focal cerebral ischemia in rats. Stroke 29, 1972-1998. doi: 10.1161/01.STR.29.9.1972

Lim, S. A., Kang, U. J., and McGehee, D. S. (2014). Striatal cholinergic interneuron regulation and circuit effects. Front. Synaptic Neurosci. 6:22. doi: 10.3389/fnsyn. 2014.00022

Lindau, N. T., Bänninger, B. J., Gullo, M., Good, N. A., Bachmann, L. C., Starkey, M. L., et al. (2014). Rewiring of the corticospinal tract in the adult rat after unilateral stroke and anti-Nogo-A therapy. Brain 137(Pt 3), 739-756. doi: 10. 1093/brain/awt336

Lisman, J., and Spruston, N. (2010). Questions about STDP as a general model of synaptic plasticity. Front. Synaptic Neurosci. 2:140. doi: 10.3389/fnsyn.2010. 00140

Lopez-Huerta, V. G., Nakano, Y., Bausenwein, J., Jaidar, O., Lazarus, M., Cherassse, Y., et al. (2016). The neostriatum: two entities, one structure? Brain Struct. Funct. 221, 1737-1749. doi: 10.1007/s00429-015-1000-4

Lovinger, D. M. (2010). Neurotransmitter roles in synaptic modulation, plasticity and learning in the dorsal striatum. Neuropharmacology 58, 951-961. doi: 10. 1016/j.neuropharm.2010.01.008

Lucas-Meunier, E., Fossier, P., Baux, G., and Amar, M. (2003). Cholinergic modulation of the cortical neuronal network. Pflugers Arch. 446, 17-29. doi: 10.1007/s00424-002-0999-2

Lund, J. S., Yoshioka, T., and Levitt, J. B. (1993). Comparison of intrinsic connectivity in different areas of macaque monkey cerebral cortex. Cereb. Cortex 3, 148-162. doi: 10.1093/cercor/3.2.148

Mahon, S., Deniau, J. M., and Charpier, S. (2004). Corticostriatal plasticity: life after the depression. Trends Neurosci. 27, 460-467. doi: 10.1016/j.tins.2004.06.010

Makino, H., Hwang, E. J., Hedrick, N. G., and Komiyama, T. (2016). Circuit mechanisms of sensorimotor learning. Neuron 92, 705-721. doi: 10.1016/j. neuron.2016.10.029 
Markram, H., Lübke, J., Frotscher, M., Roth, A., and Sakmann, B. (1997). Physiology and anatomy of synaptic connections between thick tufted pyramidal neurones in the developing rat neocortex. J. Physiol. 500(Pt 2), 409-440. doi: 10.1113/jphysiol.1997.sp022031

Mathis, M. W., Mathis, A., and Uchida, N. (2017). Somatosensory cortex plays an essential role in forelimb motor adaptation in mice. Neuron 93, 1493.e61503.e6. doi: 10.1016/j.neuron.2017.02.049

Mathur, B. N., and Lovinger, D. M. (2012). Endocannabinoid-dopamine interactions in striatal synaptic plasticity. Front. Pharmacol. 3:66. doi: 10.1017/ S0040298217000092

Mathur, B. N., Tanahira, C., Tamamaki, N., and Lovinger, D. M. (2013). Voltage drives diverse endocannabinoid signals to mediate striatal microcircuit-specific plasticity. Nat. Neurosci. 16, 1275-1283. doi: 10.1038/nn.3478

McCann, S. K., Irvine, C., Mead, G. E., Sena, E. S., Currie, G. L., Egan, K. E., et al. (2014). Efficacy of antidepressants in animal models of ischemic stroke: a systematic review and meta-analysis. Stroke 45, 3055-3063. doi: 10.1161/ STROKEAHA.114.006304

McFarland, N. R., and Haber, S. N. (2000). Convergent inputs from thalamic motor nuclei and frontal cortical areas to the dorsal striatum in the primate. J. Neurosci. 20, 3798-3813. doi: 10.1523/JNEUROSCI.20-10-03798.2000

McFarland, N. R., and Haber, S. N. (2002). Thalamic relay nuclei of the basal ganglia form both reciprocal and nonreciprocal cortical connections, linking multiple frontal cortical areas. J. Neurosci. 22, 8117-8132. doi: 10.1523/JNEUROSCI.2218-08117.2002

McGehee, D. S., Heath, M. J., Gelber, S., Devay, P., and Role, L. W. (1995). Nicotine enhancement of fast excitatory synaptic transmission in CNS by pre-synaptic receptors. Science 269, 1692-1696. doi: 10.1126/science.7569895

Melzer, S., Gil, M., Koser, D. E., Michael, M., and Huang, K. W. (2017). Distinct corticostriatal GABAergic neurons modulate striatal output neurons and motor activity article distinct corticostriatal GABAergic neurons modulate striatal output neurons and motor activity. Cell Rep. 19, 1045-1055. doi: 10.1016/j. celrep.2017.04.024

Miri, A., Warriner, C. L., Seely, J. S., Elsayed, G. F., Cunningham, J. P., Churchland, M. M., et al. (2017). Behaviorally selective engagement of short-latency effector pathways by motor cortex. Neuron 95, 683.e11-696.e11. doi: 10.1016/j.neuron. 2017.06.042

Molina-Luna, K., Hertler, B., Buitrago, M. M., and Luft, A. R. (2008). Motor learning transiently changes cortical somatotopy. Neuroimage 40, 1748-1754. doi: 10.1016/j.neuroimage.2007.11.018

Monfils, M. H., Plautz, E. J., and Kleim, J. A. (2005). In search of the motor engram: motor map plasticity as a mechanism for encoding motor experience. Neuroscientist 11, 471-483. doi: 10.1177/1073858405278015

Monfils, M. H., VandenBerg, P. M., Kleim, J. A., and Teskey, G. C. (2004). Longterm potentiation induces expanded movement representations and dendritic hypertrophy in layer V of rat sensorimotor cortex. Cereb. Cortex 14, 586-593. doi: 10.1093/cercor/bhh020

Mosberger, A. C., Miehlbradt, J. C., Bjelopoljak, N., Schneider, M. P., Wahl, A. S., Ineichen, B. V., et al. (2018). Axotomized corticospinal neurons increase supra-lesional innervation and remain crucial for skilled reaching after bilateral pyramidotomy. Cereb. Cortex 28, 625-643. doi: 10.1093/cercor/ bhw 405

Murphy, T. H., and Corbett, D. (2009). Plasticity during stroke recovery: from synapse to behaviour. Nat. Rev. Neurosci. 10, 861-872. doi: 10.1038/nrn2735

Napieralski, J. A., Butler, A. K., and Chesselet, M. F. (1996). Anatomical and functional evidence for lesion-specific sprouting of corticostriatal input in the adult rat. J. Comp. Neurol. 373, 484-497. doi: 10.1002/(SICI)10969861(19960930)373:4<484::AID-CNE2>3.0.CO;2-Y

Neafsey, E. J., and Sievert, C. (1982). A second forelimb motor area exists in rat frontal cortex. Brain Res. 232, 151-156. doi: 10.1016/0006-8993(82)90617-5

Nudo, R. J., Milliken, G. W., Jenkins, W. M., and Merzenich, M. M. (1996a). Use dependent alterations of movement representations in primary motor cortex of adult squirrel monkeys. J. Neurosci. 16, 785-807.

Nudo, R. J., Wise, B. M., SiFuentes, F., and Milliken, G. W. (1996b). Neural substrates for the effects of rehabilitative training on motor recovery after ischemic infarct. Science 272, 1791-1794.

Nudo, R. J., Plautz, E. J., and Frost, S. B. (2001). Role of adaptive plasticity in recovery of function after damage to motor cortex. Muscle Nerve 24, 1000-1019. doi: $10.1002 /$ mus. 1104
Ogura, T., Ogata, M., Akita, H., Jitsuki, S., Akiba, L., Noda, K., et al. (2005). Impaired acquisition of skilled behavior in rotarod task by moderate depletion of striatal dopamine in a pre-symptomatic stage model of Parkinson's disease. Neurosci. Res. 51, 299-308. doi: 10.1016/j.neures.2004.12.006

O'Hare, J., Calakos, N., and Yin, H. H. (2018). Recent insights into corticostriatal circuit mechanisms underlying habits. Curr. Opin. Behav. Sci. 20, 40-46. doi: 10.1016/j.cobeha.2017.10.001

O’Hare, J. K., Ade, K. K., Sukharnikova, T., Van Hooser, S. D., Palmeri, M. L., Yin, H. H., et al. (2016). Pathway-specific striatal substrates for habitual behavior. Neuron 89, 472-479. doi: 10.1016/j.neuron.2015.12.032

Olson, L., Seiger, A., and Fuxe, K. (1972). Heterogeneity of striatal and limbic dopamine innervation: highly fluorescent islands in developing and adult rats. Brain Res. 44, 283-288. doi: 10.1016/0006-8993(72)90385-X

Owen, S. F., Berke, J. D., and Kreitzer, A. C. (2018). Fast-spiking interneurons supply feedforward control of bursting, calcium, and plasticity for efficient learning. Cell 172, 683.e15-695.e15. doi: 10.1016/j.cell.2018.01.005

Papale, A. E., and Hooks, B. M. (2018). Circuit changes in motor cortex during motor skill learning. Neuroscience 368, 283-297. doi: 10.1016/j.neuroscience. 2017.09.010

Paré, D., and Smith, Y. (1996). Thalamic collaterals of corticostriatal axons: their termination field and synaptic targets in cats. J. Comp. Neurol. 372, 551-567. doi: 10.1002/(SICI)1096-9861(19960902)372:4<551::AID-CNE5>3.0.CO;2-3

Park, H., Popescu, A., and Poo, M. M. (2014). Essential role of presynaptic NMDA receptors in activity-dependent BDNF secretion and corticostriatal LTP. Neuron 84, 1009-1022. doi: 10.1016/j.neuron.2014.10.045

Parr-Brownlie, L. C., and Hyland, B. I. (2005). Bradykinesia induced by dopamine D2 receptor blockade is associated with reduced motor cortex activity in the rat. J. Neurosci. 25, 5700-5709. doi: 10.1523/JNEUROSCI.0523-05.2005

Penfield, W., and Rasmussen, T. (1950). The Cerebral Cortex of Man. New York, NY: MacMillan Press.

Perrin, E., and Venance, L. (2019). Bridging the gap between striatal plasticity and learning. Curr. Opin. Neurobiol. 54, 104-112. doi: 10.1016/j.conb.2018.09.007

Peters, A. J., Chen, S. X., and Komiyama, T. (2014). Emergence of reproducible spatiotemporal activity during motor learning. Nature 510, 263-267. doi: 10. 1038/nature13235

Peters, A. J., Liu, H., and Komiyama, T. (2017). Learning in the rodent motor cortex. Annu. Rev. Neurosci. 40, 77-97. doi: 10.1146/annurev-neuro-072116031407

Pompeiano, M., Palacios, J. M., and Mengod, G. (1992). Distribution and cellular localization of mRNA coding for 5-HT1A receptor in rat brain: correlation with receptor binding. J. Neurosci. 12, 440-453. doi: 10.1523/JNEUROSCI.12-0200440.1992

Porter, J. T., Cauli, B., Tsuzuki, K., Lambolez, B., Rossier, J., and Audinat, E. (1999). Selective excitation of subtypes of neocortical interneurons by nicotinic receptors. J. Neurosci. 19, 5228-5235. doi: 10.1523/JNEUROSCI.19-13-05228. 1999

Pruitt, D. T., Schmid, A. N., Danaphongse, T. T., Flanagan, K. E., Morrison, R. A., Kilgard, M. P., et al. (2016). Forelimb training drives transient map reorganization in ipsilateral motor cortex. Behav. Brain Res. 313, 10-16. doi: 10.1016/j.bbr.2016.07.005

Puig, M. V., Artigas, F., and Celada, P. (2005). Modulation of the activity of pyramidal neurons in rat prefrontal cortex by raphe stimulation in vivo: involvement of serotonin and GABA. Cereb. Cortex 15, 1-14. doi: 10.1093/ cercor/bhh104

Qu, M., Mittmann, T., Luhmann, H. J., Schleicher, A., and Zilles, K. (1998). Longterm changes of ionotropic glutamate and GABA receptors after unilateral permanent focal cerebral ischemia in the mouse brain. Neuroscience 85, 29-43. doi: 10.1016/S0306-4522(97)00656-8

Ramanathan, D., Conner, J. M., and Tuszynski, M. H. (2006). A form of motor cortical plasticity that correlates with recovery of function after brain injury. Proc. Natl. Acad. Sci. U.S.A. 103, 11370-11375. doi: 10.1073/pnas.060106 5103

Ramanathan, D., Tuszynski, M. H., and Conner, J. M. (2009). The basal forebrain cholinergic system is required specifically for behaviorally mediated cortical map plasticity. J. Neurosci. 29, 5992-6000. doi: 10.1523/JNEUROSCI.0230-09. 2009

Ramanathan, D. S., Guo, L., Gulati, T., Davidson, G., Hishinuma, A. K., Won, S. J., et al. (2018). Low-frequency cortical activity is a neuromodulatory target that 
tracks recovery after stroke. Nat. Med. 24, 1257-1267. doi: 10.1038/s41591-0180058-y

Reed, A., Riley, J., Carraway, R., Carrasco, A., Perez, C., Jakkamsetti, V., et al. (2011). Cortical map plasticity improves learning but is not necessary for improved performance. Neuron 70, 121-131. doi: 10.1016/j.neuron.2011.02.038

Reidler, P., Thierfelder, K. M., Fabritius, M. P., Sommer, W. H., Meinel, F. G., Dorn, F., et al. (2018). Thalamic diaschisis in acute ischemic stroke: occurrence, perfusion characteristics, and impact on outcome. Stroke 49, 931-937. doi: 10.1161/STROKEAHA.118.020698

Reiner, A., Jiao, Y., Del Mar, N., Laverghetta, A. V., and Lei, W. L. (2003). Differential morphology of pyramidal tract-type and intratelencephalically projecting-type corticostriatal neurons and their intrastriatal terminals in rats. J. Comp. Neurol. 457, 420-440. doi: 10.1002/cne.10541

Reynolds, J. N., Hyland, B. I., and Wickens, J. R. (2001). A cellular mechanism of reward-related learning. Nature 413, 67-70. doi: 10.1038/35092560

Salinas, A. G., Davis, M. I., Lovinger, D. M., and Mateo, Y. (2016). Dopamine dynamics and cocaine sensitivity differ between striosome and matrix compartments of the striatum. Neuropharmacology 108, 275-283. doi: 10.1016/ j.neuropharm.2016.03.049

Sanes, J. N., and Donoghue, J. P. (2000). Plasticity and primary motor cortex. Annu. Rev. Neurosci. 23, 393-415. doi: 10.1146/annurev.neuro.23.1.393

Savasta, M., Dubois, A., and Scatton, B. (1986). Autoradiographic localization of D1 dopamine receptors in the rat brain with [3H]SCH 23390. Brain Res. 375, 291-301. doi: 10.1016/0006-8993(86)90749-3

Schubring-Giese, M., Molina-Luna, K., Hertler, B., Buitrago, M. M., Hanley, D. F., and Luft, A. R. (2007). Speed of motor re-learning after experimental stroke depends on prior skill. Exp. Brain Res. 181, 359-365. doi: 10.1007/s00221-0070930-3

Scullion, K., Boychuk, J. A., Yamakawa, G. R., Rodych, J. T., Nakanishi, S. T., Seto, A., et al. (2013). Serotonin 1A receptors alter expression of movement representations. J. Neurosci. 33, 4988-4999. doi: 10.1523/JNEUROSCI.4241-12. 2013

Seitz, R. J., Azari, N. P., Knorr, U., Binkofski, F., Herzog, H., and Freund, H. J. (1999). The role of diaschisis in stroke recovery. Stroke 30, 1844-1850. doi: 10.1161/01.STR.30.9.1844

Shen, W., Flajolet, M., Greengard, P., and Surmeier, D. J. (2008). Dichotomous dopaminergic control of striatal synaptic plasticity. Science 321, 848-851. doi: $10.1126 /$ science. 1160575

Shen, W., Hamilton, S. E., Nathanson, N. M., and Surmeier, D. J. (2005). Cholinergic suppression of KCNQ channel currents enhances excitability of striatal medium spiny neurons. J. Neurosci. 25, 7449-7458. doi: 10.1523/ JNEUROSCI.1381-05.2005

Shigemoto, R., and Mizuno, N. (2000). "Metabotropic glutamate receptorsimmunocytochemical and in situ hybridization analyses," in Handbook of Chemical Neuroanatomy: Glutamate, Vol. 18, eds O. P. Ottersen and J. StormMathisen (New York, NY: Elsevier Press), 63-98.

Shmuelof, L., and Krakauer, J. W. (2011). Are we ready for a natural history of motor learning? Neuron 72, 469-476. doi: 10.1016/j.neuron.2011.10.017

Silberberg, G., and Bolam, J. P. (2015). Local and afferent synaptic pathways in the striatal microcircuitry. Curr. Opin. Neurobiol. 33, 182-187. doi: 10.1016/j.conb. 2015.05.002

Singh, A. M., and Staines, W. R. (2015). The effects of acute aerobic exercise on the primary motor cortex. J. Mot. Behav. 47, 328-339. doi: 10.1080/00222895.2014. 983450

Smith, J. B., Klug, J. R., Ross, D. L., Howard, C. D., Hollon, N. G., Ko, V. I., et al. (2016). Genetic-based dissection unveils the inputs and outputs of striatal patch and matrix compartments. Neuron 91, 1069-1084. doi: 10.1016/j.neuron.2016. 07.046

Smith, Y., Bolam, J. P., and Krosigk, M. V. (1990). Topographical and synaptic organization of the GABA-containing pallido subthalamic projection in the rat. Eur. J. Neurosci. 2, 500-511. doi: 10.1111/j.1460-9568.1990.tb00441.x

Smith, Y., Galvan, A., Ellender, T. J., Doig, N., Villalba, R. M., Huerta-Ocampo, I., et al. (2014). The thalamostriatal system in normal and diseased states. Front. Syst. Neurosci. 8:5. doi: 10.3389/fnsys.2014.00005

Spalletti, C., Alia, C., Lai, S., Panarese, A., Conti, S., Micera, S., et al. (2017). Combining robotic training and inactivation of the healthy hemisphere restores pre-stroke motor patterns in mice. eLife 6:e28662. doi: 10.7554/eLife.28662
Surmeier, D. J., Plotkin, J., and Shen, W. (2009). Dopamine and synaptic plasticity in dorsal striatal circuits controlling action selection. Curr. Opin. Neurobiol. 19, 621-628. doi: 10.1016/j.conb.2009.10.003

Tennant, K. A., Taylor, S. L., White, E. R., and Brown, C. E. (2017). Optogenetic rewiring of thalamocortical circuits to restore function in the stroke injured brain. Nat. Commun. 23:15879. doi: 10.1038/ncomms15879

Tepper, J. M., Abercrombie, E. D., and Bolam, J. P. (2007). Basal ganglia macrocircuits. Prog. Brain Res. 160, 3-7. doi: 10.1016/S0079-6123(06)60001-0

Tepper, J. M., Koós, T., and Wilson, C. J. (2004). GABAergic microcircuits in the neostriatum. Trends Neurosci. 27, 662-669. doi: 10.1016/j.tins.2004.08.007

Tice, M. A., Hashemi, T., Taylor, L. A., and McQuade, R. D. (1996). Distribution of muscarinic receptor subtypes in rat brain from postnatal to old age. Dev. Brain. Res. 92, 70-76. doi: 10.1016/0165-3806(95)01515-9

Tombari, D., Loubinoux, I., Pariente, J., Gerdelat, A., Albucher, J. F., Tardy, J., et al. (2004). A longitudinal fMRI study: in recovering and then in clinically stable sub-cortical stroke patients. Neuroimage 23, 827-839. doi: 10.1016/j. neuroimage.2004.07.058

Touvykine, B., Mansoori, B. K., Jean-Charles, L., Deffeyes, J., Quessy, S., and Dancause, N. (2016). The effect of lesion size on the organization of the ipsilesional and contralesional motor cortex. Neurorehabil. Neural Repair 30, 280-292. doi: 10.1177/1545968315585356

Turrigiano, G. G., and Nelson, S. B. (2004). Homeostatic plasticity in the developing nervous system. Nat. Rev. Neurosci. 5, 97-107. doi: 10.1038/nrn1327

Uryu, K., MacKenzie, L., and Chesselet, M. F. (2001). Ultrastructural evidence for differential axonal sprouting in the striatum after thermocoagulatory and aspiration lesions of the cerebral cortex in adult rats. Neuroscience 105, 307-316. doi: 10.1016/S0306-4522(01)00203-2

Vahlsing, H. L., and Feringa, E. R. (1980). A ventral uncrossed corticospinal tract in the rat. Exp. Neurol. 70, 282-287. doi: 10.1016/0014-4886(80)90027-8

von Monakow, C. (1914). Lokalisation im Gehirn und Funktionelle Sta'rungen Induziert Durch Kortikale Läsionen. Wiesbaden: Bergmann JF.

Wada, E., McKinnon, D., Heinemann, S., Patrick, J., and Swanson, L. W. (1990). The distribution of mRNA encoded by a new member of the neuronal nicotinic acetylcholine receptor gene family (a5) in the rat central nervous system. Brain Res. 526, 45-53. doi: 10.1016/0006-8993(90)90248-A

Wada, E., Wada, K., Boulter, J., Deneris, E., Heinemann, S., Patrick, J., et al. (1989). Distribution of a2, a3, a4, and b2 neuronal nicotinic receptor subunit mRNAs in the central nervous system: a hybridization histochemical study in the rat. J. Comp. Neurol. 284, 314-335. doi: 10.1002/cne.902840212

Wahl, A. S., Omlor, W., Rubio, J. C., Chen, J. L., Zheng, H., Schröter, A., et al. (2014). Neuronal repair. asynchronous therapy restores motor control by rewiring of the rat corticospinal tract after stroke. Science 344, 1250-1255. doi: $10.1126 /$ science. 1253050

Wahl, A. S., and Schwab, M. E. (2014). Finding an optimal rehabilitation paradigm after stroke: enhancing fiber growth and training of the brain at the right moment. Front. Hum. Neurosci. 8:381. doi: 10.3389/fnhum.2014. 00381

Walker, M. P., Brakefield, T., Hobson, J. A., and Stickgold, R. (2003). Dissociable stages of human memory consolidation and reconsolidation. Nature 425, 616620. doi: 10.1038/nature01930

Wang, K. S., McClure, J. P., Alselehdar, S. K., and Kanta, V. (2015). Direct and indirect pathways of the basal ganglia: opponents or collaborators? Front. Neuroanat. 9:20. doi: 10.3389/fnana.2015.00020

Wang, L., Conner, J. M., Nagahara, A. H., and Tuszynski, M. H. (2016). Rehabilitation drives enhancement of neuronal structure in functionally relevant neuronal subsets. Proc. Natl. Acad. Sci. U.S.A. 113, 2750-2755. doi: $10.1073 /$ pnas. 1514682113

Wang, Z., and McCormick, D. A. (1993). Control of firing mode of corticotectal and corticopontine layer $\mathrm{V}$ burst-generating neurons by norepinephrine, acetylcholine, and 1S,3R-ACPD. J. Neurosci. 13, 2199-2216. doi: 10.1523/ JNEUROSCI.13-05-02199.1993

Ward, N. S., Brown, M. M., Thompson, A. J., and Frackowiak, R. S. J. (2003). Neural correlates of motor recovery after stroke: a longitudinal fMRI study. Brain 126, 2476-2496. doi: 10.1093/brain/awg245

Weiler, N., Wood, L., Yu, J., Solla, S. A., and Shepherd, G. M. G. (2008). Top-down laminar organization of the excitatory network in motor cortex. Nat. Neurosci. 11, 360-366. doi: 10.1038/nn2049 
Wenger, E., Brozzoli, C., Lindenberger, U., and Lövdén, M. (2017). Expansion and renormalization of human brain structure during skill acquisition. Trends Cogn. Sci. 21, 930-939. doi: 10.1016/j.tics.2017.09.008

Wilson, C. J. (1987). Morphology and synaptic connections of crossed corticostriatal neurons in the rat. J. Comp. Neurol. 263, 567-580. doi: 10.1002/ cne.902630408

Winship, I. R., and Murphy, T. H. (2008). In vivo calcium imaging reveals functional rewiring of single somatosensory neurons after stroke. J. Neurosci. 28, 6592-6606. doi: 10.1523/JNEUROSCI.0622-08.2008

Withers, G. S., and Greenough, W. T. (1989). Reach training selectively alters dendritic branching in subpopulations of layer II-III pyramids in rat motorsomatosensory forelimb cortex. Neuropsychologia 27, 61-69. doi: 10.1016/00283932(89)90090-0

Witte, O. W. (1998). Lesion-induced plasticity as a potential mechanism for recovery and rehabilitative training. Curr. Opin. Neurol. 11, 655-662. doi: 10. 1097/00019052-199812000-00008

Wu, Y. W., Kim, J. I., Tawfik, V. L., Lalchandani, R. R., Scherrer, G., and Ding, J. B. (2015). Input- and cell-type-specific endocannabinoiddependent LTD in the striatum. Cell Rep. 10, 75-87. doi: 10.1016/j.celrep.2014. 12.005

Xu, H., Perez, S., Cornil, A., Detraux, B., Prokin, I., Cui, Y., et al. (2018). Dopamine-endocannabinoid interactions mediate spike-timing-dependent potentiation in the striatum. Nat. Commun. 9:4118. doi: 10.1038/s41467-01806409-5

$\mathrm{Xu}, \mathrm{M}$., Li, L., and Pittenger, C. (2016). Ablation of fast-spiking interneurons in the dorsal striatum, recapitulating abnormalities seen post-mortem in Tourette syndrome, produces anxiety and elevated grooming. Neuroscience 324, 321329. doi: 10.1016/j.neuroscience.2016.02.074

Yamawaki, N., Borges, K., Suter, B. A., Harris, K. D., and Shepherd, G. M. G. (2014). A genuine layer 4 in motor cortex with prototypical synaptic circuit connectivity. eLife 3:e05422. doi: 10.7554/eLife.05422

Yin, H. H. (2017). The basal ganglia in action. Neuroscientist 23, 299-313. doi: $10.1177 / 1073858416654115$

Yin, H. H., Prasad-Mulcare, S., Hilário, M. R. F., Clouse, E., Davis, M. I., Hansson, A. C., et al. (2009). Dynamic reorganization of striatal circuits during the acquisition and consolidation of a skill. Nat. Neurosci. 12, 333-341. doi: 10. 1038/nn.2261

Zeiler, S. R., Gibson, E. M., Hoesch, R. E., Li, M. Y., Worley, P. F., O’Brien, R. J., et al. (2013). Medial premotor cortex shows a reduction in inhibitory markers and mediates recovery in a mouse model of focal stroke. Stroke 44, 483-489. doi: 10.1161/STROKEAHA.112.676940

Conflict of Interest Statement: The authors declare that the research was conducted in the absence of any commercial or financial relationships that could be construed as a potential conflict of interest.

Copyright (c) 2019 Balbinot and Schuch. This is an open-access article distributed under the terms of the Creative Commons Attribution License (CC BY). The use, distribution or reproduction in other forums is permitted, provided the original author(s) and the copyright owner(s) are credited and that the original publication in this journal is cited, in accordance with accepted academic practice. No use, distribution or reproduction is permitted which does not comply with these terms. 